Article

\title{
Investigation of Integral and Differential Characteristics of Variatropic Structure Heavy Concretes by Ultrasonic Methods
}

\author{
Levon R. Mailyan ${ }^{1}$, Sergey A. Stel'makh ${ }^{2}$, Evgenii M. Shcherban' ${ }^{2, *} \mathbb{0}$, Alexander K. Khalyushev ${ }^{3}$,
} Alla S. Smolyanichenko ${ }^{4}$, Alexander K. Sysoev ${ }^{5}$, Ivan A. Parinov ${ }^{6}$ and Alexander V. Cherpakov ${ }^{6,7}$

\section{check for} updates

Citation: Mailyan, L.R.; Stel'makh, S.A.; Shcherban', E.M.; Khalyushev, A.K.; Smolyanichenko, A.S.; Sysoev, A.K.; Parinov, I.A.; Cherpakov, A.V. Investigation of Integral and Differential Characteristics of Variatropic Structure Heavy Concretes by Ultrasonic Methods. Appl. Sci. 2021, 11, 3591. https://doi.org/10.3390/ app11083591

Academic Editor: Doo-Yeol Yoo

Received: 10 March 2021

Accepted: 14 April 2021

Published: 16 April 2021

Publisher's Note: MDPI stays neutral with regard to jurisdictional claims in published maps and institutional affiliations.

Copyright: (c) 2021 by the authors. Licensee MDPI, Basel, Switzerland. This article is an open access article distributed under the terms and conditions of the Creative Commons Attribution (CC BY) license (https:// creativecommons.org/licenses/by/ $4.0 /)$.
1 Department of Roads, Don State Technical University, 344000 Rostov-on-Don, Russia; lrm@aaanet.ru

2 Department of Engineering Geology, Bases and Foundations, Don State Technical University, 344000 Rostov-on-Don, Russia; sergej.stelmax@mail.ru

3 Department of Technological Engineering and Expertise in the Construction Industry, Don State Technical University, 344000 Rostov-on-Don, Russia; khaljushev@mail.ru

4 Department of Water Supply and Sewerage, Don State Technical University, 344000 Rostov-on-Don, Russia; arpis-2006@mail.ru

5 Department of Building Materials, Don State Technical University, 344000 Rostov-on-Don, Russia; aksisoevrgsu@yandex.ru

6 I. I. Vorovich Mathematics, Mechanics, and Computer Science Institute, Southern Federal University, 344090 Rostov-on-Don, Russia; parinov_ia@mail.ru (I.A.P.); alex837@yandex.ru (A.V.C.)

7 Department of Information Systems in Construction, Don State Technical University, 344000 Rostov-on-Don, Russia

* Correspondence: au-geen@mail.ru

\begin{abstract}
The article develops methods and methodology for experimental studies of centrifuged and vibro-centrifuged concrete products of annular cross-section. They assess the real variatropy of the structure and confirm the correctness of the accepted research. An original technique for experimental studies of the variatropy of the cross-sections of vibrated, centrifuged and vibro-centrifuged concretes is proposed to determine their integral (common) and differential (differing in layers) strength and strain characteristics and deformation diagrams. It has been proved that with vibro-centrifugation it becomes possible to obtain concretes with improved structure and higher characteristics compared with centrifugation and vibration techniques. Experimental studies of the differential characteristics of centrifuged and vibro-centrifuged concretes under compression and tension revealed that the outer layer of concrete had the best characteristics after centrifugation and vibro-centrifugation, and the inner layer had the worst ones. The three-layer model of the variatropic structure for centrifuged and vibro-centrifuged concrete has been experimentally confirmed. The concrete of the outer layers had the highest strength and modulus of elasticity and the least deformability; the concrete of the inner layers had the lowest strength and modulus of elasticity and the highest deformability; and the concrete of the middle layers had average characteristics. The deformation diagrams of centrifuged and vibro-centrifuged concretes were also differentiated by layers, confirming the variatropy of the structure of such concretes. The deformation diagrams for the outer concrete layer demonstrated the highest strength; the diagrams for the inner concrete layer showed the lowest strength; and the diagrams for the middle concrete layer corresponded to mean characteristics.
\end{abstract}

Keywords: vibrated concrete; centrifuged concrete; vibro-centrifuged concrete; integral characteristics; differential characteristics; variatropic structure; ultrasonic method

\section{Introduction}

During operation, concrete undergoes various influences, the result of which are strength changes over time. This change can take place in three directions:

(i) The strength of concrete may increase under favorable temperature and humidity conditions due to the continuing hydration of cement; 
(ii) Micro-fractures of the structure appear in concrete under the influence of the environment; however, the continuing hydration of the cement compensates for the decrease in strength from these micro-fractures, and the strength of concrete remains constant as a whole;

(iii) There is an intense accumulation of microdestructions in the concrete structure under the influence of the environment; due to unfavorable temperature and humidity conditions, the cement hydration is either completely absent or proceeds extremely slowly, and as a result, a steady decrease in the strength of concrete occurs.

The first case is observed in the underground part of structures, where there are appropriate conditions for the continuation of cement hydration and the growth of concrete strength. The second case is typical for a small transition zone from the ground to the aboveground part of structures or for warm and humid areas of their operation. The third case is dominant for the aboveground part of the structures.

A decrease in the strength of concrete is one of the factors that reduce the bearing capacity of structures during their operation and, accordingly, reduce their reliability and safety level. It is important to control the strength of concrete structures, especially prestressed ones. It should be emphasized that the control should be non-destructive, while it should allow for assessing the strength of concrete at any stage of the operation of structures and degradation of the concrete structure.

The purpose of this paper is to study the characteristics of reinforced concrete structures with annular cross-sections, in particular, integral (common in cross-section) and differential (differing in cross-section) structural characteristics of vibrated, centrifuged and vibro-centrifuged concretes of variatropic cross-sections using ultrasonic research methods.

The novelty of this work can be highlighted in three aspects: theory, application and recommendation. The theoretical aspect consists of obtaining a broader picture of the variatropy of concrete in structures of the annular section. The development of universal methods for studying the variatropy and integral and differential properties of concretes obtained by the methods of vibration, centrifugation and vibrocentrifugation can be attributed to a novelty in a practical aspect. The recommendation aspect for the future direction of work is connected with the further development of new and improvement of existing practical methods for obtaining accurate quantitative and qualitative data for concretes of variatropic structures. It is planned to develop a universal technique for other types of variatropic concretes, such as lightweight, cellular, multilayer and so on. Moreover, it is recommended to apply more refined methods, for example, methods of mathematical modeling, the finite element method, in order to determine and design the main characteristics of reinforced concrete and concrete structures, both load-bearing and fencing, demonstrating a variatropy of concrete structure.

The paper is organized as follows: Section 2 presents an overview of modern theoretical and experimental methods for investigation and characterization of structural materials, in particular, resonance and ultrasonic methods of their non-destructive researching. Application of the ultrasonic method for the control of the properties of concrete is discussed in Section 3. Section 4 describes the technologies used for the manufacture of vibrated, centrifuged and vibro-centrifuged concretes, and methods of their testing. The experimental results to study integral and differential characteristics of the considered kinds of concretes are the focus of Section 5. Section 6 is devoted to final conclusions.

\section{Overview of Theoretical and Experimental Methods}

Currently, there are many methods of non-destructive testing of concrete characteristics, including strength properties [1-8]. Non-destructive research methods can be divided into direct methods for calculating a linear response of material structure, reflecting its properties, for example, hardness or elasticity under pressure, and indirect methods, implying the transmission of various wave pulses of energy through the body, functionally reflecting its characteristics. In these studies, various types of wave sources of oscillations can be used, including the transmitting and receiving of elements of the sensors. 
Based on the excitation type of oscillation sources, the methods of non-destructive testing can be characterized as (i) X-ray methods; (ii) electromagnetic methods; (iii) acoustic methods; (iv) impact methods; and (v) combined methods.

Some of them are presented in reviews of works [5-7]. Most often in practice, acoustic and shock methods of non-destructive testing are used. The resonance and ultrasonic methods of non-destructive research of structural materials are examples of acoustic research methods.

The resonance method is based on measuring and calculating the amplitudes and spectral characteristics of a structure, and also the damping decrement of small vibrations. The longitudinal, bending and torsional oscillations of a simple rod construction can be considered as idealized ones [6-13]. The method consists of the following stages: (i) The vibration amplitudes are measured at several points of the construction at its stationary oscillations with the obtainment of dynamic images of the construction vibrations as output characteristics; (ii) the data of the vibration patterns are processed by using the analytical Fourier transform, and the vibration resonances are selected; (iii) using the application of inverse methods for restoring properties using analytical dependences, for example, based on the Bernoulli beam theory, one can calculate the elastic modulus $E$, shear modulus $G$ and Poisson's ratio $v$ of the considered structure.

The use of indirect analysis of the dependences of material properties, defectiveness, stiffness of individual nodes on the amplitudes $E \sim f(A)$ and frequencies $E \sim f\left(\omega_{n}\right)$ can be obtained on the basis of analytical functional dependencies of regression analysis [14-17]. The analytical and numerical methods of the oscillation theory allow us study the vibrations of elastic solids with a more complex shape [18-20].

A simpler method is the use of an acoustic non-destructive testing method based on measuring the speed of a propagating oscillation wave between two points, which in turn can be classified in the dependence on the relative position of the transmitting and receiving transducers of acoustic waves. The frequencies between 20 and $200 \mathrm{kHz}$ represent the most commonly used frequency range for ultrasonic frequency analysis, applicable in practice. Practical approaches of various authors show the positive aspects of using ultrasonic scanning of materials [21-23].

Their applicability under certain conditions is determined by such details as access to the surface of the sample from only one or both sides, as well as the ability to test the required material properties (strength, presence or absence of defects, etc.). The physical quantities that must be measured in acoustic methods are wave velocity, damping and frequency spectrum composition. In this case, the most sensitive measurements are the direct changes in the wave, propagating from a vibration source to a receiver.

The longitudinal $V_{L}$ and the transverse $V_{T}$ velocities of sound are measured between the amplitude peaks of the propagation of the excited wave with the corresponding oscillation mode through two points. A review of works on the estimation of the dependences of strength of concrete $R_{\mathcal{c}}$ on velocity parameters is presented in [24,25].

Russian State Standards give two approximating formulae for this kind of relationship (GOST 17624-2012):

$$
R_{c}=a_{0}+a_{1} V_{L} R_{c}=b_{0} e^{b V_{L}}
$$

where $a_{0}, a_{1}, b, b_{0}$ are parameters that should be selected based on the measurement results.

Today there is not a single-value mathematical formula for converting the speed of an ultrasonic pulse into strength of concrete, with a relative error of at least $5-7 \%$. The general rule (see above) is that higher speed of an ultrasonic pulse correlates with higher strength of concrete, at other equal external conditions.

In the dependence "strength of concrete-speed of ultrasonic pulse", various constants can be used, and it can be described by more complex functional linear dependencies. These coefficients, respectively, depend on the environment parameters, internal factors, describing the model of the research sample, the microstructure of material, saturation with a liquid and structure heterogeneity (defectiveness). These parameters unambiguously reduce the accuracy of non-destructive testing methods (NDTs) for the previously set 
dependencies, when setting up the testing device on laboratory samples. To overcome this drawback, some authors [26-28] propose to use methods of statistical processing of experimental data. In this case, multifactor data analysis can be used.

\section{Application of the Ultrasonic Method for the Control of Concrete Properties}

One of the advantages of using non-destructive testing methods (NDTs) for studying concrete is the speed of the measurement of properties with a certain degree of reliability. NDTs are used mainly in the construction industry for inspection control of the concrete strength of buildings and structures, as well as for determining the transfer and tempering strength of concrete in reinforced concrete structures. However, in practice, there is an insufficient number of effective methods for controlling the strength of concrete in exploited structures, in which a decrease in its strength occurs due to the appearance of damage in the structure [29-41]. In [1], an attempt was made to develop a special method for non-destructive testing of the concrete strength of the operated contact network supports. At the same time, the possibility of using the two most common control methods (chipping and elastic rebound) was investigated.

The chipping method is laborious and inefficient; moreover, it damages a structure, which is unacceptable in the case of damage of concrete throughout the structure. By this method, the strength of concrete is estimated at a shallow depth of up to $20 \mathrm{~mm}$. The deeper part, which as a rule has a large amount of microdamage, remains out of reach.

For high-precision control of concrete strength using the method of elastic rebound, it is required to construct calibration dependences of strength on the height of the striker bounce, which is almost impossible to obtain for operating supports. In the absence of such dependences, the accuracy of assessing the strength of concrete is within $\pm 50 \%$ and, as a rule, is overestimated. This conclusion is confirmed by the results of mechanical tests of the construction supports, carried out simultaneously with non-destructive tests.

The rebound method is unsuitable for concretes with strength exceeding $50 \mathrm{MPa}$; it requires adjustment when controlling the strength of concrete with curved surfaces, as well as wet concrete. The rebound method allows one to control the strength of concrete of the surface layers of structures and cannot be used to control the inner layers that are most damaged during operation. This method is suitable for testing the strength of non-cracked concrete. With near cracks or damage, the method does not reflect the actual strength of the concrete.

Ultrasonic vibrations are used to assess the damage in the concrete structure [5-17]. The main indicator of damage in this case is the ratio of the propagation time of the ultrasound pulse in the direction perpendicular to the stressed reinforcement to the time of propagation of the ultrasound pulse along this reinforcement. As studies show, when damage accumulates in concrete, the time of ultrasound pulse propagation changes most intensively in the direction perpendicular to the stressed reinforcement [1].

In the centrifuged unstressed construction supports, due to their conical shape and closed cross-section, under the action of temperature and humidity factors, a stressed state arises in which tangential stresses are dominant. Theoretically, these stresses are two times higher than the stresses directed along the generatrix of the supports, and therefore, in these construction supports, the appearance and accumulation of damage occurs mainly on the planes parallel to the generatrix of the support surface. The methods of measurements of characteristics in unstressed centrifuged construction supports are the same as in prestressed ones.

The speed of propagation of ultrasound pulse is one of the characteristics of the quality of concrete [2]. For the actual control of the strength of concrete on the basis of the ultrasound transmission rate, a special experiment was carried out, and a calibration dependence "concrete strength—ultrasound pulse transmission rate" was constructed. The experimental procedure and processing of these results corresponded to Russian GOST 17624-2012 "Concrete. Ultrasonic Method for Determination of Strength". To measure the propagation time of an ultrasound pulse in the samples, the through sounding method 
was used, and therefore the transducers of the device were installed on the opposite sides of the sample. To ensure reliable contact between the concrete and the working surfaces of the transducers, technical Vaseline was used.

The evaluation of the heterogeneity of the properties of centrifuged concrete was carried out in two stages [2]. At the first and second stages, the properties of a freshly laid concrete mixture and the properties of hardened concrete were studied, respectively. The study of the inhomogeneity of concrete properties was carried out on molded cylindric specimens. The heterogeneity of the properties of centrifuged samples along their height was investigated, which is equivalent to the differentiation of these properties along the wall thickness of the annular section of a reinforced concrete product. The reliability of the results was confirmed by a fivefold repetition of the experiments, and the coefficient of variation of the studied property was used to assess the reliability. Moreover, the mutual influence of technological and manufacture factors on the properties of centrifuged concrete and its heterogeneity along the wall thickness was investigated by means of mathematical planning of the experiment and mathematical modeling. The simplest models that are convenient for analysis are the equations obtained in the implementation of a full factorial experiment. The reliability of the obtained regression equations was checked by the value of the Fisher criterion, which should not exceed the critical value for a given level of significance and a selected number of degrees of freedom. Graphical interpretation of the obtained regression equations allows one to qualitatively and quantitatively assess the influence of variable factors on the assessment criteria [2].

In [3], a technique for assessing the design characteristics of centrifuged reinforced concrete annular columns was investigated based on the propagation velocity of ultrasound in concrete. Using this technique, a comparison was made between one- and two-stage molding processes. In [29], ultrasonic testing was proposed for the quantitative assessment of transverse and longitudinal cracks using the time and energy characteristics of ultrasonic signals and assessment of the parameters of ultrasound propagation. The method was tested in the field conditions of the Latvian Railway by comparative testing of defect-free and cracked sleepers. Non-linear ultrasonic measurements for real-time monitoring of the damage of concrete, caused by various loads, were performed in [30]. This work focused on the efficiency of the proposed method for monitoring micro-damage of concrete elements caused by mechanical loading.

The authors of [31] studied the interaction of ultrasonic waves with partially closed cracks on the surface of concrete structures and, based on the measurements, estimated the width of the area of microcracks around the cracks. To optimize the sensitivity of the method, it was proposed to use correctly positioned triangular prisms [32]. The transducers are placed on the correct side of the prism, thus changing their orientation and the direction of the emitted ultrasonic wave relative to the wall surface. In [33], tests were carried out on various concrete cylinders damaged by compression. The growth of damage was monitored using linear and nonlinear ultrasonic methods in order to better understand the processes of mechanical destruction of concrete and to identify the possibilities and limitations of the used non-destructive testing methods. The purpose of the designation method of concrete quality, proposed in [34], is to determine the damage degree of concrete relative to its original and undamaged state. This method is based on a comparison of laboratory and ultrasonic tests and is adjusted taking into account the characteristics of the concrete mixtures under study. The results show that the considered method is quite accurate and sensitive to very low and very high damage.

\section{Materials and Methods}

In practice, centrifugation is the most effective and widespread method of forming long products with an annular cross-section. This method is based on the compaction of a concrete mixture by squeezing out part of the water in a rotating form under the influence of centrifugal forces. The advantages of the centrifuged method of molding products with an annular section in comparison with other methods of compacting a concrete mixture are 
a high degree of compaction, reduced water permeability and water absorption of concrete. The resulting product has a variation in properties over the section. The use of centrifugation with other types of processing can improve the final quality in terms of material properties. To investigate this issue, the studies described in this article were conducted.

During the development of the experimental combined setup for centrifugation and vibro-centrifugation [42-44] and the choice of the parameters of the studied concrete samples, we investigated their density and porosity both as common in cross-section as in separate layers.

We analyzed the methods and devices used for their implementation, aimed at studying the structure of heavy concrete. The structures under consideration had small physical volumes. The samples also had linearly extended structures. Ultrasonic flaw detectors use a mode in which the ultrasound echo is displayed as peaks in a horizontal line showing its amplitude. The time between two peaks is measured and the speed of the traveling wave between the two pickup points is calculated. For this purpose, the best and simplest research method was the construction of the distribution of velocities in different parts of the samples and averaging of their parameters associated with the accuracy of the device and the spread of the data obtained. The devices were configured only to measure the velocity parameters of the wave from the peak data of the vibration amplitudes. The phase characteristics of the traveling waves were not the objective of the research.

In practice, three devices from different manufacturers were used: (i) Pulsar-2.2, (ii) UKS-MG4S, and (iii) NOVOTEST IPSM-U. The characteristics of the devices were as follows: ranges of speed measurement, respectively, (i) 1000 to 10,000 m/s, (ii) 1000 to $8000 \mathrm{~m} / \mathrm{s}$ and (iii) 01000 to $5000 \mathrm{~m} / \mathrm{s}$; the accuracy of the instruments, estimated experimentally, was, respectively, $0.3 \%, 0.5 \%$ and $0.7 \%$.

The ultrasonic device "Pulsar-2.2" has proved itself the best of all of them, since it has wider ranges for measuring the velocity and propagation time of ultrasonic waves, especially in the case of end-to-end ultrasound examination of the material. Additionally, "Pulsar-2.2" has a smaller discreteness of indication of the propagation time of ultrasonic vibrations than the two other tested devices. The combination of these factors, which makes it possible to carry out comprehensive studies of the integral and differential characteristics of heavy concretes with a variatropic structure, confirmed the expediency of its application in this study.

The model "Pulsar-2.2" is improved relative to its counterparts on the market. It is included in the unified register of measuring instruments of the Russian Federation. It is also applied on the basis of Russian GOSTs of interstate importance. This device is one of the recognized leaders in the market for testing and researching building materials, products and structures, and in particular, stone, such as heavy concrete. At the same time, its accuracy is quite high and allows one to determine the difference in structure between layers of concrete with a variatropic section. Thus, this device is appropriate for such a study.

The characteristics of the integral porosity of concrete (the average radius $r_{a v}$ and the uniformity of the distribution of pores $\alpha$ in concrete) were determined by using the graphic-analytical method of M. I. Brusser [45] on the kinetics of water absorption. Endto-end ultrasonic examination of centrifuged concrete was carried out using a meter of time and velocity of the propagation of ultrasound waves, "Pulsar-2.2", designed to assess the strength, density and modulus of elasticity of properties and defectoscopy of building materials in time, propagation velocity and shape of ultrasonic pulses. The measurements were carried out in accordance with Russian GOST 17624-2012. The setup during end-toend ultrasound examination and a general view of test samples are shown in Figure 1. The technical characteristics of the device "Pulsar 2.2" are presented in Table 1. 


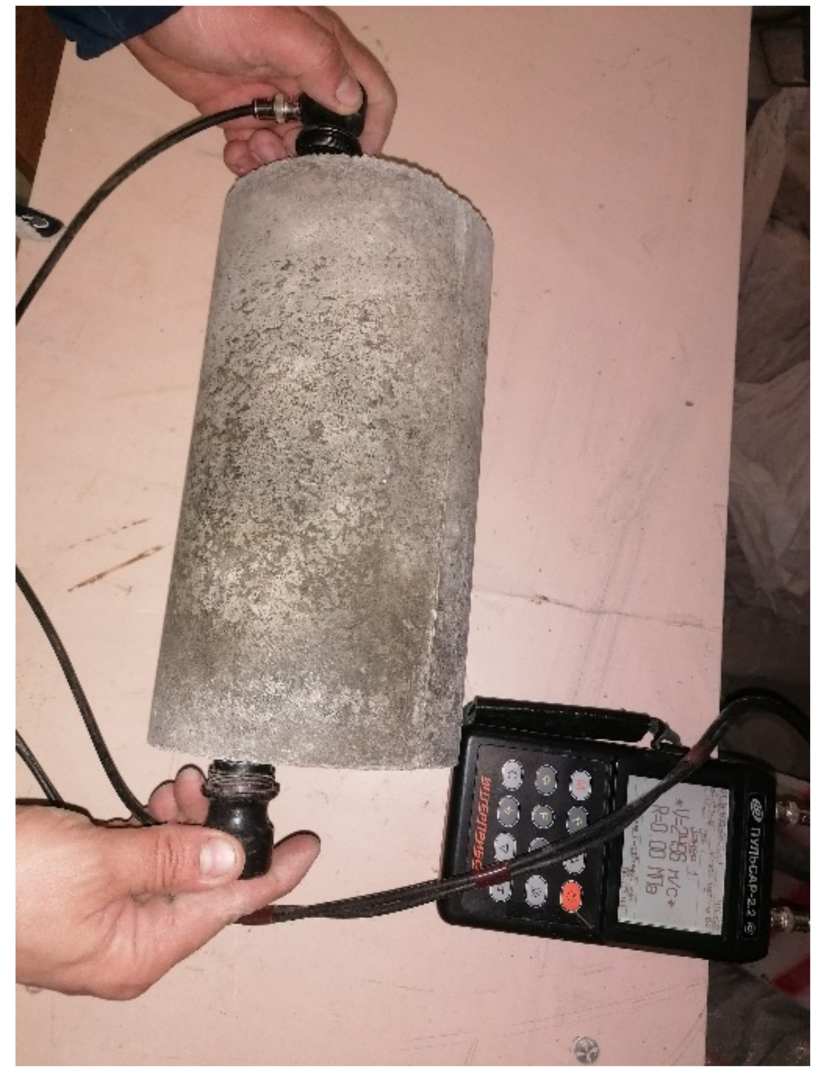

(a)

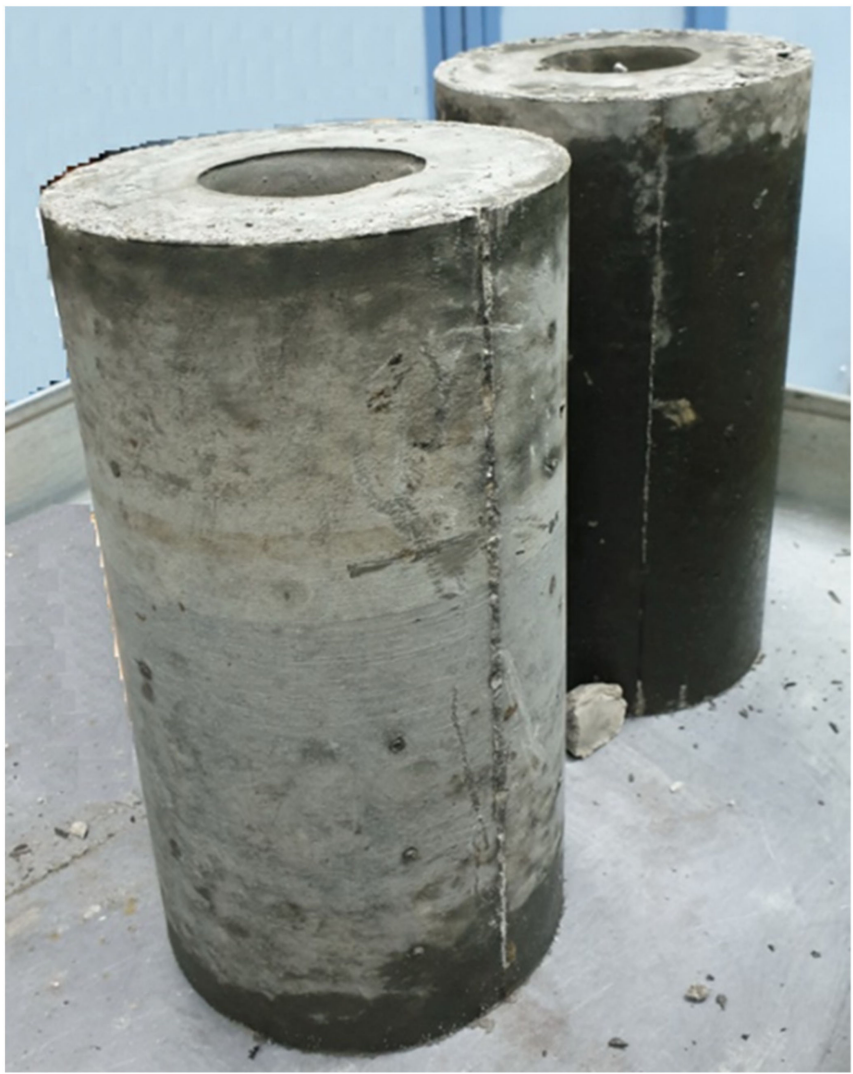

(b)

Figure 1. (a) Setup during end-to-end ultrasound examination, and (b) general view of test samples.

Table 1. Technical characteristics of device "Pulsar 2.2".

\begin{tabular}{|c|c|c|c|}
\hline No. & Indicator Name & Units & Indicator \\
\hline 1 & Measurement range of the propagation velocity of ultrasonic waves & $\mathrm{m} / \mathrm{s}$ & $1000-10,000$ \\
\hline 2 & Measurement range of the propagation time of ultrasonic waves & $\mu \mathrm{s}$ & $10-100$ \\
\hline 3 & Measurement base for surface end-to-end ultrasound examination & $\mathrm{mm}$ & $120 \pm 1$ \\
\hline 4 & Power consumption, no more than & W & 0.7 \\
\hline 5 & Weight of the device with a complete set, no more than & $\mathrm{kg}$ & 1.5 \\
\hline 6 & $\begin{array}{l}\text { Overall dimensions } \\
\text { (length } \times \text { width } \times \text { height): } \\
\text { (i) electronic unit } \\
\text { (ii) surface ultrasound probe } \\
\text { (iii) transducer of end-to-end ultrasound examination }\end{array}$ & $\begin{array}{l}\mathrm{mm}^{3} \\
\mathrm{~mm}^{3} \\
\mathrm{~mm}^{2}\end{array}$ & $\begin{array}{c}205 \times 115 \times 35 \\
250 \times 50 \times 100 \\
\varnothing 36 \times 62\end{array}$ \\
\hline
\end{tabular}

The adopted instrumental methods for investigating concrete prototypes and the used instruments and equipment [43-49] made it possible to assess the picture of the real variatropy of the structure and conclude that the accepted direction of research is correct. In total, 9 vibrated, centrifuged and vibro-centrifuged samples of annular cross-section were manufactured and tested (Figure 2), each with an outer diameter $D=450 \mathrm{~mm}$; an inner hole diameter $d=150 \mathrm{~mm}$ and a total height $H=1200 \mathrm{~mm}$. In the experiments, the manufacturing technology was varied. The following conventions for the manufacturing technology were adopted using the following sample codes:

$\mathrm{V}$-vibration,

C-centrifugation,

VC-vibro-centrifugation. 


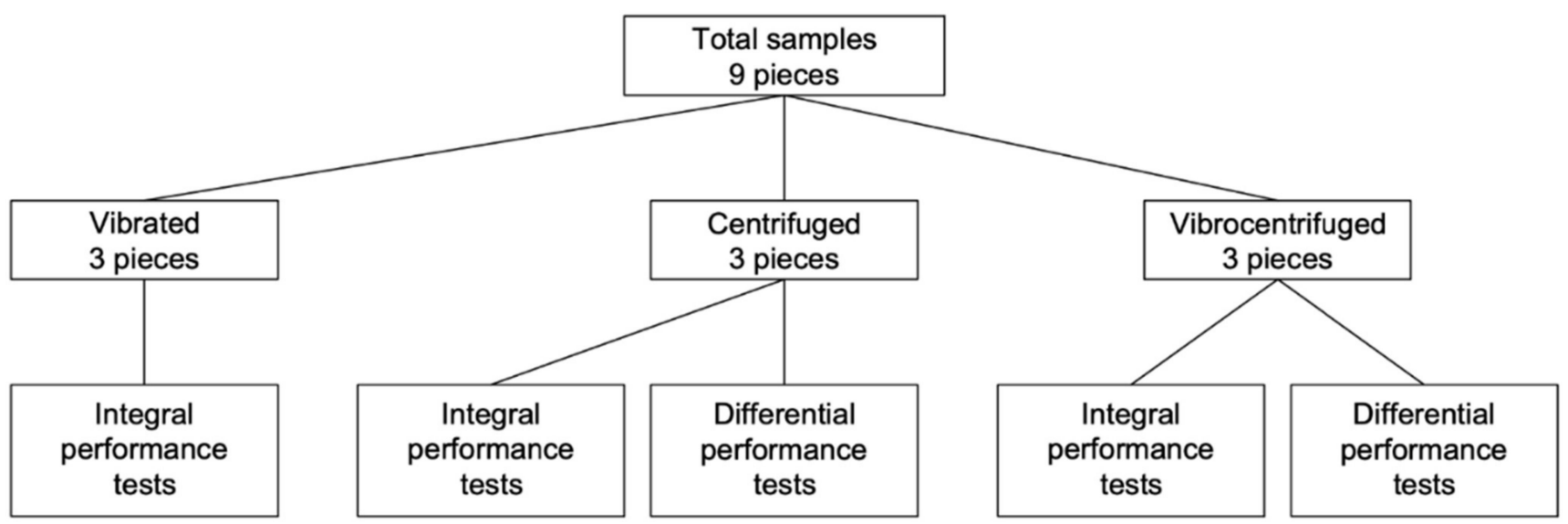

Figure 2. Schedule of experimental studies of integral and differential characteristics of vibrated, centrifuged and vibrocentrifuged samples.

The problem of assessing the influence of manufacturing technology (vibration, centrifugation, vibration centrifugation) on the integral (common, averaged over the crosssection) and differential (differing in the layers of the cross-section) characteristics of concrete was investigated:

(i) Density $\rho$;

(ii) Axial compression strength (cubic $R_{b, c u b}$ and prismatic $R_{b}$ );

(iii) Limiting strains during axial compression $\varepsilon_{b}$;

(iv) Axial tensile $R_{b t}$ and flexural tensile strength $R_{b t b, i}$;

(v) Limiting strains during axial tension $\varepsilon_{b t}$;

(vi) Elastic modulus (in compression $E_{b}$ and tension $E_{b t}$ );

(vii) Diagram "stress $\sigma_{b}$-strain $\varepsilon_{b}$ " in compression;

(viii) Diagram "stress $\sigma_{b t}$-strain $\varepsilon_{b t}$ " in tension.

In the experiment, the following data were taken for aggregates:

(i) Granite crushed stone of the JSC "Pavlovsk Nerud" (Russia) with a fraction of 5-20 mm;

(ii) Quartz sand of the Grushevskoye deposit (Russia), $\mathrm{M}_{\mathrm{k}}=2.0$.

Figure 3 shows a scheme for obtaining small-sized concrete samples for testing. Quadrants A-D of manufactured basic full-size annular cross-section specimens (in plan): on the left, for the study of integral characteristics (1-four cubes with an edge of $150 \mathrm{~mm}$ in axial compression $R_{b, \text { cub }}, 1-4$ levels of quadrant A in height; 2-one prism of $150 \times 150 \times 600 \mathrm{~mm}^{3}$ for the study of tension in bending $R_{b t b}$, 5th level of quadrant $\mathrm{A}$ in height; 3-two prisms of $150 \times 150 \times 600 \mathrm{~mm}^{3}$ for axial compression $R_{b}, 1-2$ levels of quadrant $B$ in height; 4 - two prisms of $150 \times 150 \times 600 \mathrm{~mm}^{3}$ for the study of axial tension $R_{b t}, 1-2$ levels of quadrant $\mathrm{C}$ in height); on the right, for the study of differential characteristics (1-nine cubes with an edge of $50 \mathrm{~mm}$ in axial compression $R_{b, c u b, i}, 1$ st level of quadrant D in height; 2 -nine prisms of $50 \times 50 \times 200 \mathrm{~mm}^{3}$ for the study of tension in bending $R_{b t b, i}$, 2 nd level of quadrant $\mathrm{D}$ in height; 3-nine prisms of $50 \times 50 \times 200 \mathrm{~mm}^{3}$ for axial compression $R_{b, i}$, 3rd level of quadrant D in height; 4 -nine prisms of $50 \times 50 \times 200 \mathrm{~mm}^{3}$ for axial tension $R_{b t, i}, 4$ th level of quadrant $\mathrm{D}$ in height).

As a binder, Portland cement was used with a normal density of $25.5 \%$, a specific surface area of $365 \mathrm{~m}^{2} / \mathrm{kg}$, an activity of $5.9 \mathrm{MPa}$ (in bending) and $51.5 \mathrm{MPa}$ (in compression), and setting times as follows: start at $1 \mathrm{~h}$ and $5 \mathrm{~min}$, end at $3 \mathrm{~h}$ and $15 \mathrm{~min}$.

Through the results of calculations, the composition of the concrete mixture was determined: a fraction of coarse aggregate (mixture 5.0-20.0), crushed stone-1203 kg, sand $-696 \mathrm{~kg}$, cement $-416 \mathrm{~kg}$, water-181 L, average density of the concrete mixture$2498 \mathrm{~kg} / \mathrm{m}^{3}$. 


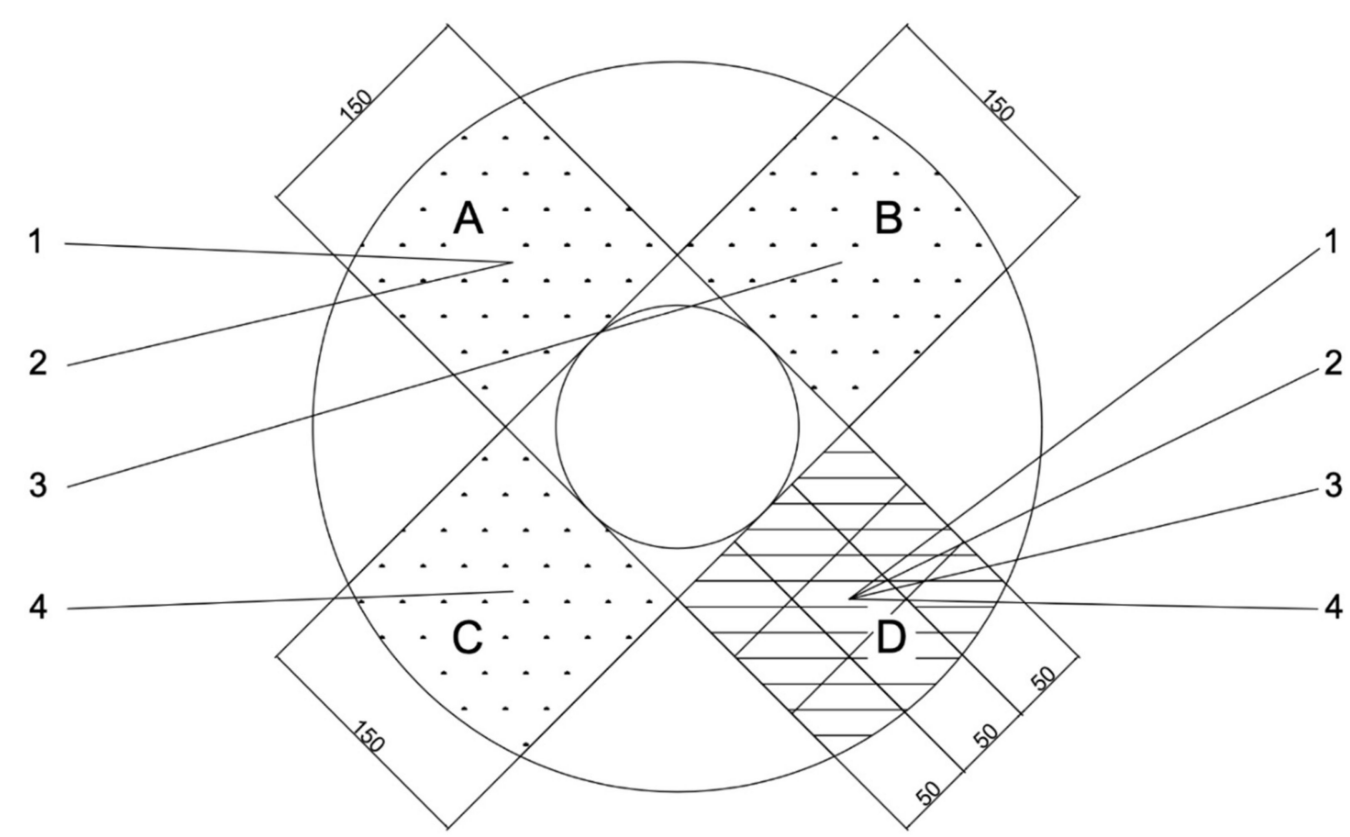

Figure 3. Scheme for obtaining small-sized concrete samples for testing.

The test method has distinctive features in that each manufactured base sample was used in several types of tests. One of the basic samples was tested at the ages of 7,28 and 180 days.

The first type of tests was carried out to study the integral (common, cross-section averaged) characteristics of concrete. For this purpose, three conditional quadrants, A, B, C, were selected from the total annular cross-section (see Figure 3), from which small-sized specimens were cut for subsequent tests under axial compression, axial tension and tension in bending (see Figures 4 and 5).

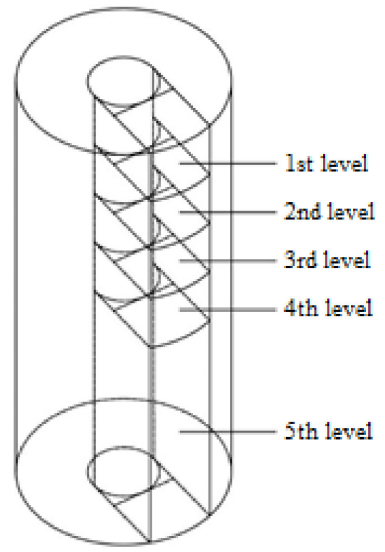

(a)

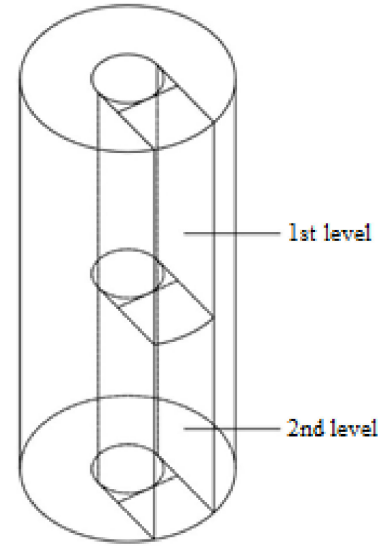

(b)

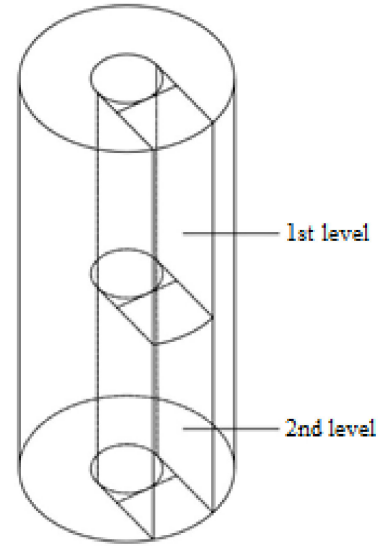

(c)

Figure 4. Scheme of obtaining small-size concrete specimens from quadrants A, B, C along the height of experimental basic full-size specimens of annular cross-section for testing integral characteristics: (a) quadrant A; (b) quadrant B; (c) quadrant C. 


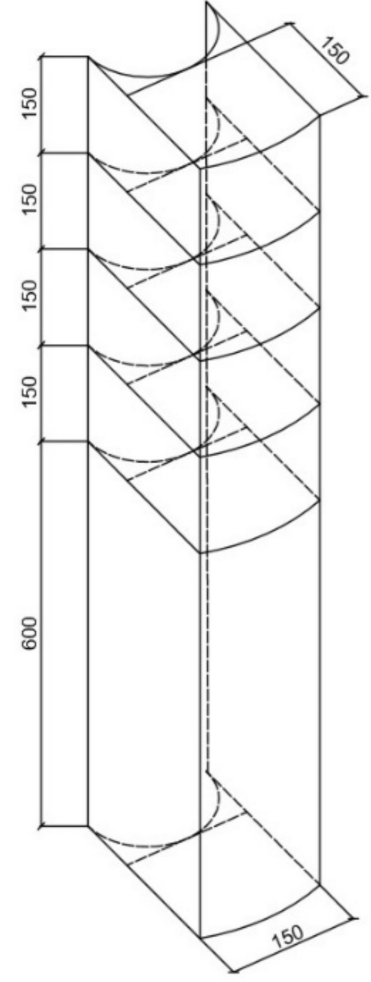

(a)

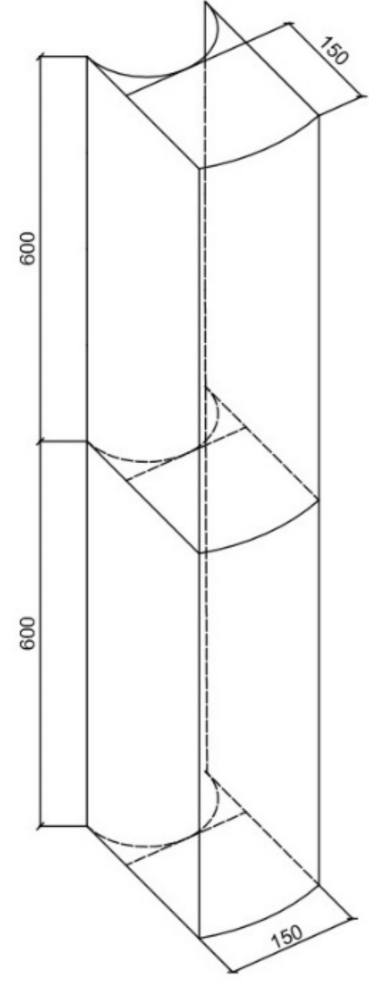

(b)

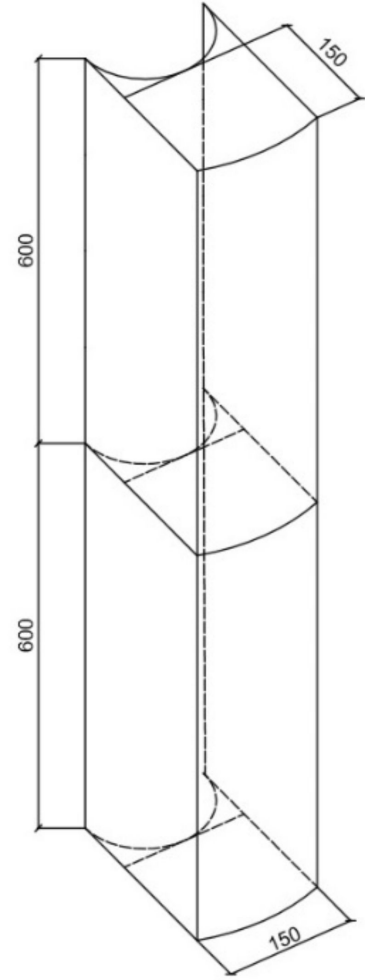

(c)

Figure 5. Experimental small-size concrete samples from quadrants (a) A, (b) B, (c) C of experimental basic full-size samples of annular cross-section for the study of integral characteristics.

All samples were cut and tested in accordance with the requirements of the Russian GOST 28570-2019. For axial compression tests, 4 cubes with dimensions of $150 \times 150 \times 150 \mathrm{~mm}^{3}$ were cut out from quadrant $A$ (1-4 levels of the quadrant $A$ in height), and 1 prism with dimensions of $150 \times 150 \times 600 \mathrm{~mm}^{3}$ was cut out from quadrant $A$ for tensile bending tests (5th level of quadrant $\mathrm{A}$ in height). Further, for axial compression tests, 2 prisms with dimensions $150 \times 150 \times 600 \mathrm{~mm}^{3}$ were cut out from quadrant B (levels 1st and 2nd of the quadrant B in height). Finally, for axial tension tests, 2 prisms with dimensions of $150 \times 150 \times 600 \mathrm{~mm}^{3}$ were also cut out from quadrant $C$, (levels 1 st and 2 nd of the quadrant $C$ in height).

We obtained the following:

(i) The values of $R_{b, \text { cub }}$ in the results of testing cubes on axial compression;

(ii) The values of $R_{b}, \varepsilon_{b R}, R_{b t}, \varepsilon_{b t R}, E_{b}=E_{b t}$ and the deformation diagram " $\sigma_{b}-\varepsilon_{b}$ " in the results of testing prisms on axial compression;

(iii) The values of $R_{b t}$ and deformation diagram " $\sigma_{b t}-\varepsilon_{b t}$ " in the results of testing prisms on axial tension;

(iv) The values of $R_{b t b}$ in the results of testing prisms on tension in bending.

The second type of test was carried out to study the differential (differing in crosssection) characteristics of concrete. For this purpose, quadrant $\mathrm{D}$ was selected in the common cross-section of the base sample (see Figure 3). The entire cross-section of the quadrant $D$ was conventionally divided into 3 layers (external, middle and internal) of $50 \mathrm{~mm}$ thickness each, the characteristics of which were determined (see Figures 6 and 7). 


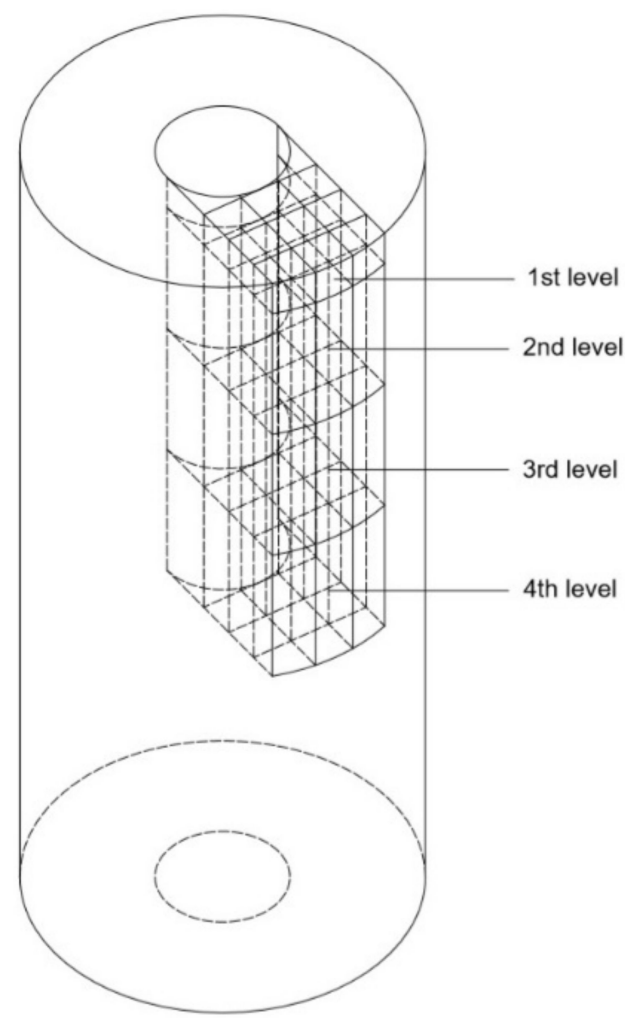

Figure 6. Scheme of obtaining small-size concrete specimens from quadrant $\mathrm{D}$ in height of experimental basic full-size specimens of annular cross-section for testing differential characteristics.

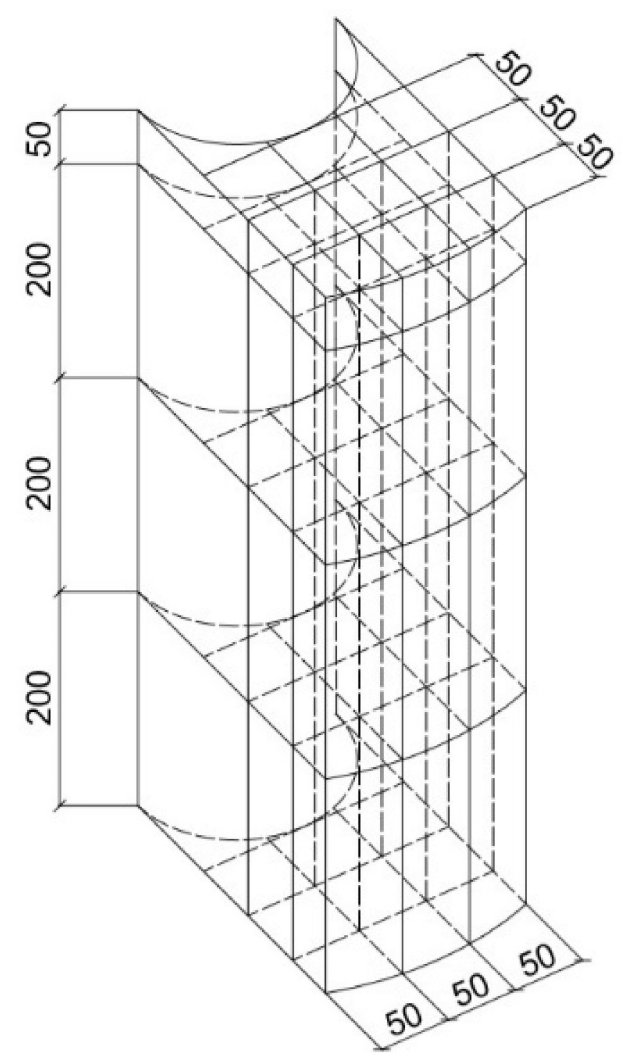

Figure 7. Experimental small-size concrete samples from quadrant D of experimental basic full-size samples of annular cross-section to study differential characteristics. 
For the tests on axial compression and tension from quadrant $\mathrm{D}$ of the same basic sample along the entire length, the following were cut out: (i) 9 cubes with dimensions of $50 \times 50 \times 50 \mathrm{~mm}^{3}$ (from 1st level of the quadrant D) for axial compression tests; (ii) 9 prisms with dimensions of $50 \times 50 \times 200 \mathrm{~mm}^{3}$ (from 2 nd level of the quadrant D) for tensile tests in bending; (iii) 9 prisms with dimensions of $50 \times 50 \times 200 \mathrm{~mm}^{3}$ (from 3rd level of the quadrant D) for axial compression tests; (iv) 9 prisms with dimensions of $50 \times 50 \times 200 \mathrm{~mm}^{3}$ (from 4 th level of the quadrant D) for axial tension tests.

We obtained (i) the values of $R_{b, c u b, i}$ in the results of testing cubes on axial compression; (ii) the values of $R_{b, i}, \varepsilon_{b R, i}, R_{b t, i}, \varepsilon_{b t R, i}, E_{b, i}=E_{b t, i}$ and the deformation diagram " $\sigma_{b, i}-\varepsilon_{b, i}$ " in the results of testing prisms on axial compression; (iii) the values of $R_{b t, i}$ and deformation diagram " $\sigma_{b t, i}-\varepsilon_{b t, i}$ " in the results of testing prisms on axial tension; (iv) the values of $R_{b t b, i}$ in the results of testing prisms on tension in bending.

It should be especially noted that only basic centrifuged and vibro-centrifuged samples were tested for integral and differential characteristics, while vibrated base samples were tested only for integral characteristics (see Figures 2 and 8).

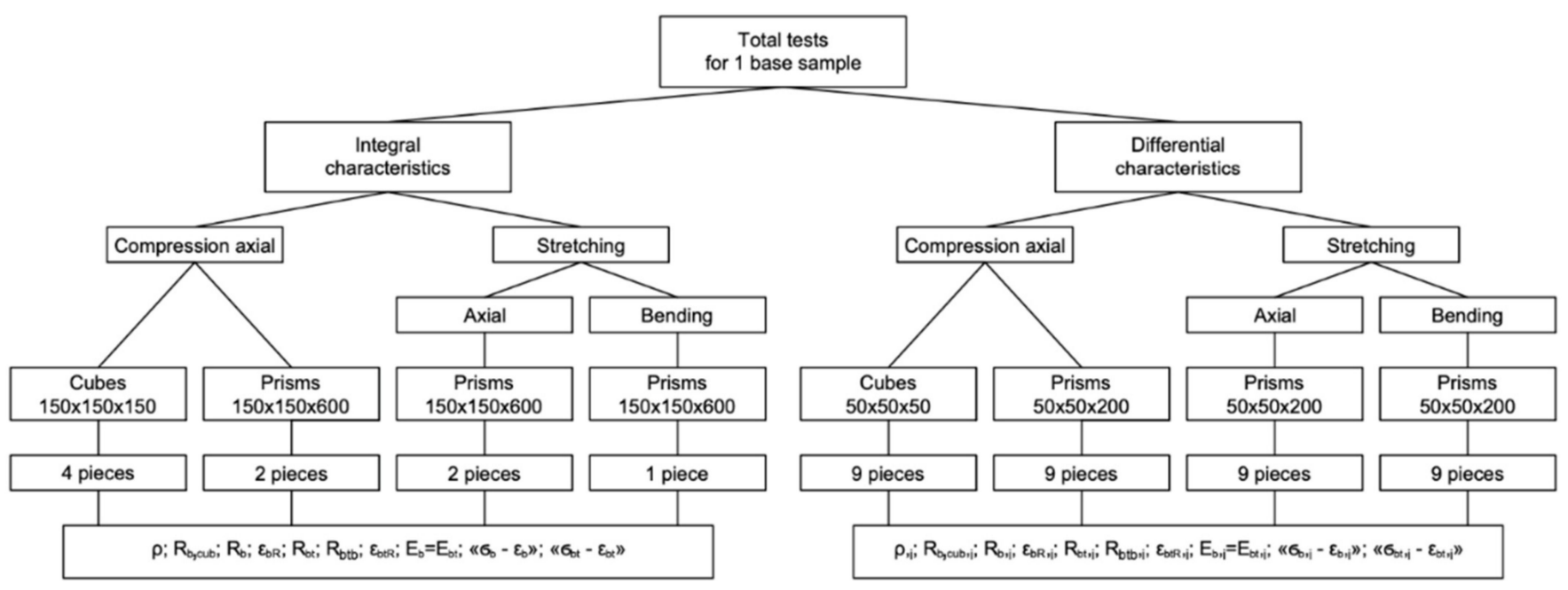

Figure 8. Schedule of experimental research of small-size concrete samples obtained from experimental base sample of annular section when vibrating (left side), centrifuging and vibro-centrifuging (left and right sides).

All samples were tested at the ages of 7,28 and 180 days in accordance with the Russian GOST 10180 and the Russian GOST 28570. That is, in the result, each baseline sample was tested at three different ages. To correctly compare the results of samples with different sizes, a scale factor was used (in Russian GOST 10180-2012, and GOST 28570-2019). Cubic samples were tested for axial compression at a constant loading rate. Axial compression testing of the prisms was carried out on an IPS-10 test press. Axial tensile tests of prisms were carried out in a special setup in an R-10 test press. The measurements of the concrete deformations of the test prisms were carried out with a chain of strain gauges with a base of $50 \mathrm{~mm}$ and dial indicators with graduations of $0.001 \mathrm{~mm}$. Experimental prisms were tested on axial compression and axial tension at a constant rate of strain in order to obtain not only the strength and deformation characteristics of concrete, but also its full deformation diagrams " $\sigma-\varepsilon$ " with descending branches. For this, we used not only tensometric, but also oscillographic equipment, which allowed one to obtain not only limiting strength, limiting strains and elastic modulus, but also their complete stress-strain diagrams under compression and tension. When tested at the same loading rate, the stepwise loading steps were approximately $0.1 R$, while when tested with a constant deformation rate, the strains of the prisms increased stepwise by $0.1 \varepsilon_{R}$ (see Figure 9). 


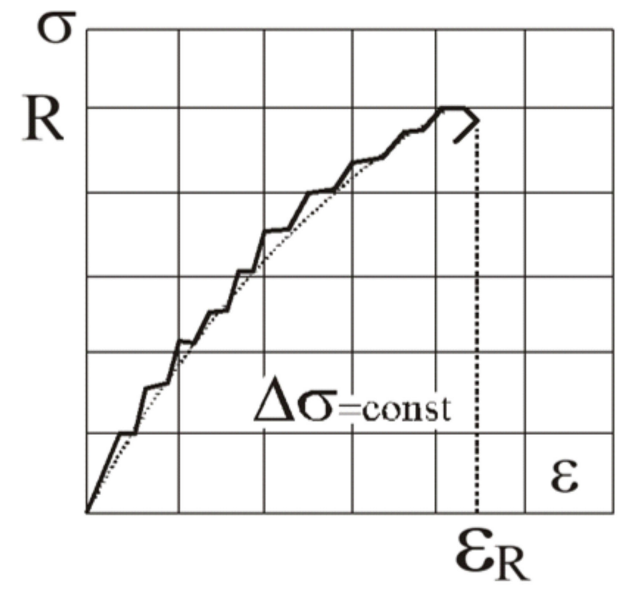

(a)

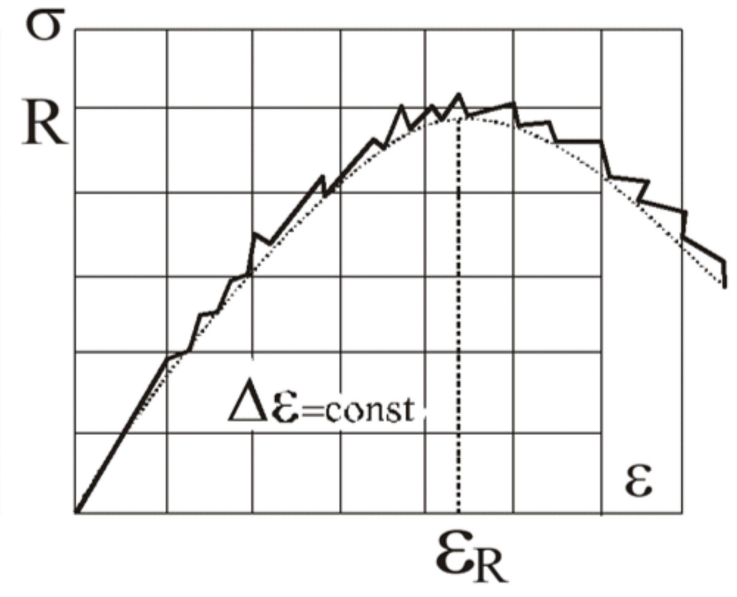

(b)

Figure 9. Test modes of experimental small-size samples: (a) in stages, with a constant loading rate; (b) in stages, with a constant rate of deformation.

In the last test mode, the load first increased, reaching a maximum, and then began to decrease with a continued increase in deformations. Thus, during the tests, the descending branch of the stress-strain diagram of concrete was recorded, which in our studies had a fairly stable outline approximately up to the value $\sigma=0.8 R$, both under compression and under tension, and then acquired an unstable character.

As a whole, we varied in the studies the following:

(i) Manufacturing technology (vibration, centrifugation, vibro-centrifugation);

(ii) Type of stress-strain state (axial compression and axial tension);

(iii) Type of sample (cubes, $50 \times 50 \times 50 \mathrm{~mm}^{3}$ and $150 \times 150 \times 150 \mathrm{~mm}^{3}$; prisms $50 \times 50 \times 200 \mathrm{~mm}^{3}$ and $\left.150 \times 150 \times 600 \mathrm{~mm}^{3}\right)$;

(iv) Test mode (with constant loading rate and constant deformation rate);

(v) Concrete age (7, 28 and 180 days).

The schedule of experimental studies of integral and differential design characteristics of vibrated, centrifuged and vibro-centrifuged samples is shown in Figure 2.

\section{Results and Discussion}

5.1. Study of the Integral Design Characteristics of Vibrated, Centrifuged and Vibro-Centrifuged Concretes

5.1.1. Research Results of the Integral Characteristics of Concrete

When analyzing the experimental results obtained, we paid especial attention to the influence of manufacturing technology. The results of experimental studies of the averaged integral characteristics of test concrete samples are shown in Table 2 and Figures 10-18.

Table 2. Results of experimental studies of the averaged integral characteristics of vibrated (V), centrifuged (C) and vibro-centrifuged (VC) test concrete samples.

\begin{tabular}{|c|c|c|c|c|c|c|c|}
\hline \multirow{2}{*}{ Characteristics of Concrete } & \multirow{2}{*}{ Age, Days } & \multicolumn{3}{|c|}{ Manufacturing Technology } & \multicolumn{3}{|c|}{ Deviations, $\%$} \\
\hline & & $\mathbf{V}$ & $\mathrm{C}$ & VC & $\Delta_{1}$ & $\Delta_{2}$ & $\Delta_{3}$ \\
\hline \multirow{3}{*}{ Density, $\mathrm{kg} / \mathrm{m}^{3}$} & 7 & 2395 & 2439 & 2445 & \multirow{3}{*}{1.8} & \multirow{3}{*}{2.1} & \multirow{3}{*}{0.2} \\
\hline & 28 & 2385 & 2428 & 2434 & & & \\
\hline & 180 & 2365 & 2406 & 2421 & & & \\
\hline
\end{tabular}


Table 2. Cont.

\begin{tabular}{|c|c|c|c|c|c|c|c|}
\hline \multirow{2}{*}{ Characteristics of Concrete } & \multirow{2}{*}{ Age, Days } & \multicolumn{3}{|c|}{ Manufacturing Technology } & \multicolumn{3}{|c|}{ Deviations, $\%$} \\
\hline & & $\mathbf{V}$ & $\mathrm{C}$ & VC & $\Delta_{1}$ & $\Delta_{2}$ & $\Delta_{3}$ \\
\hline \multicolumn{8}{|l|}{ Compressive strength, $\mathrm{MPa}$} \\
\hline \multirow{3}{*}{ (i) cubic } & 7 & 43.7 & 45.5 & 53.3 & 4.2 & 22 & 17.1 \\
\hline & 28 & 59.8 & 62.5 & 70.7 & 4.5 & 18.2 & 13.1 \\
\hline & 180 & 76.5 & 81.2 & 92.6 & 6.1 & 21 & 14 \\
\hline \multirow{3}{*}{ (ii) prismatic } & 7 & 33.3 & 34.8 & 40.4 & 4.5 & 21 & 16 \\
\hline & 28 & 45.6 & 47.6 & 53.8 & 4.4 & 18 & 13 \\
\hline & 180 & 58.4 & 61.9 & 70.5 & 6 & 20.7 & 13.9 \\
\hline \multicolumn{8}{|l|}{ Tensile strength, $\mathrm{MPa}$} \\
\hline \multirow{3}{*}{ (i) by bending } & 7 & 3.6 & 3.9 & 4.5 & 7 & 24 & 16 \\
\hline & 28 & 4.7 & 5.2 & 5.9 & 10.6 & 25.5 & 13.5 \\
\hline & 180 & 6.2 & 6.9 & 7.9 & 11.3 & 26.6 & 13.8 \\
\hline \multirow{3}{*}{ (ii) axial } & 7 & 3.3 & 3.5 & 4.1 & 6 & 24 & 16.9 \\
\hline & 28 & 4.4 & 4.6 & 5.3 & 4.4 & 20.5 & 15.2 \\
\hline & 180 & 5.8 & 6.1 & 7.1 & 5.2 & 22.4 & 16.4 \\
\hline \multirow{3}{*}{$\begin{array}{l}\text { Limiting deformations at axial } \\
\text { compression, } \mathrm{mm} / \mathrm{m} \times 10^{-3}\end{array}$} & 7 & 2.87 & 2.84 & 2.8 & 1.1 & 2.44 & 1.4 \\
\hline & 28 & 2.18 & 2.15 & 2.11 & 1.4 & 3.3 & 1.9 \\
\hline & 180 & 1.68 & 1.62 & 1.58 & 3.6 & 5.9 & 2.5 \\
\hline \multirow{3}{*}{$\begin{array}{l}\text { Limiting deformations at axial } \\
\text { tension, } \mathrm{mm} / \mathrm{m} \times 10^{-4}\end{array}$} & 7 & 1.58 & 1.55 & 1.51 & 1.9 & 4.4 & 2.6 \\
\hline & 28 & 1.19 & 1.17 & 1.13 & 1.7 & 5.3 & 3.4 \\
\hline & 180 & 0.93 & 0.9 & 0.87 & 3.2 & 6.4 & 3.3 \\
\hline \multirow{3}{*}{ Elastic modulus, $\mathrm{GPa}$} & 7 & 26.1 & 27 & 28.5 & 3.4 & 9.2 & 5.6 \\
\hline & 28 & 37.4 & 39.9 & 42.9 & 6.7 & 14.7 & 7.5 \\
\hline & 180 & 48.1 & 52.3 & 56.8 & 8.7 & 18.1 & 8.6 \\
\hline
\end{tabular}
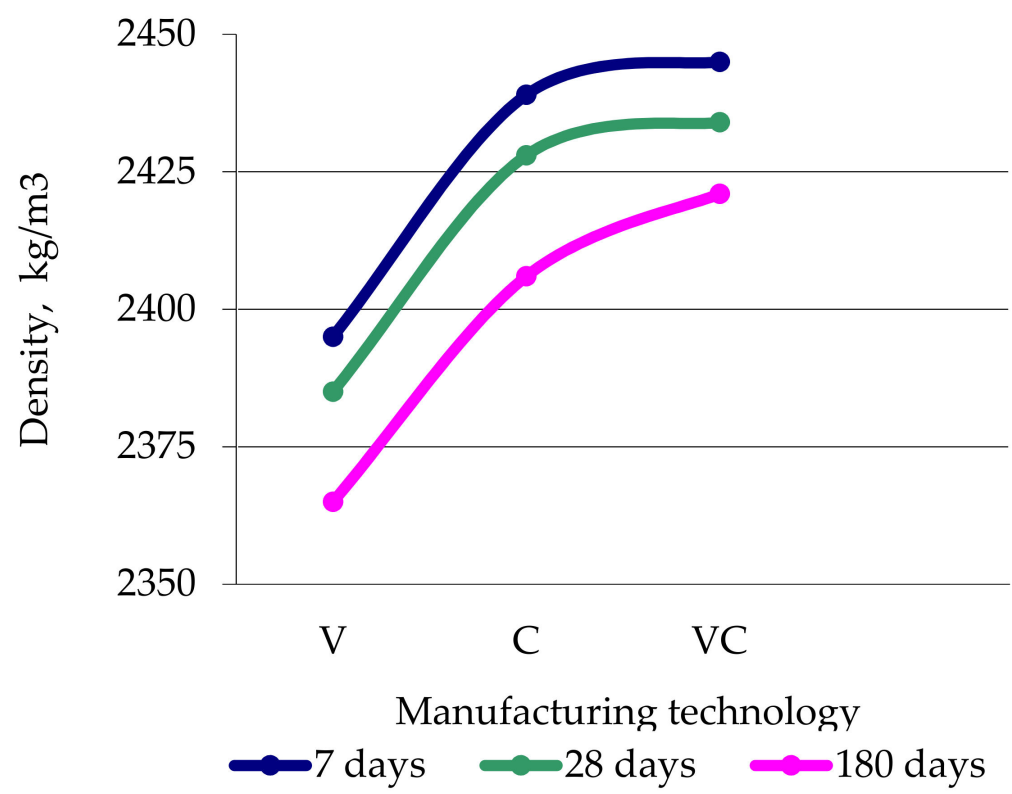

Figure 10. Dependence of the concrete density on the manufacturing technology. 


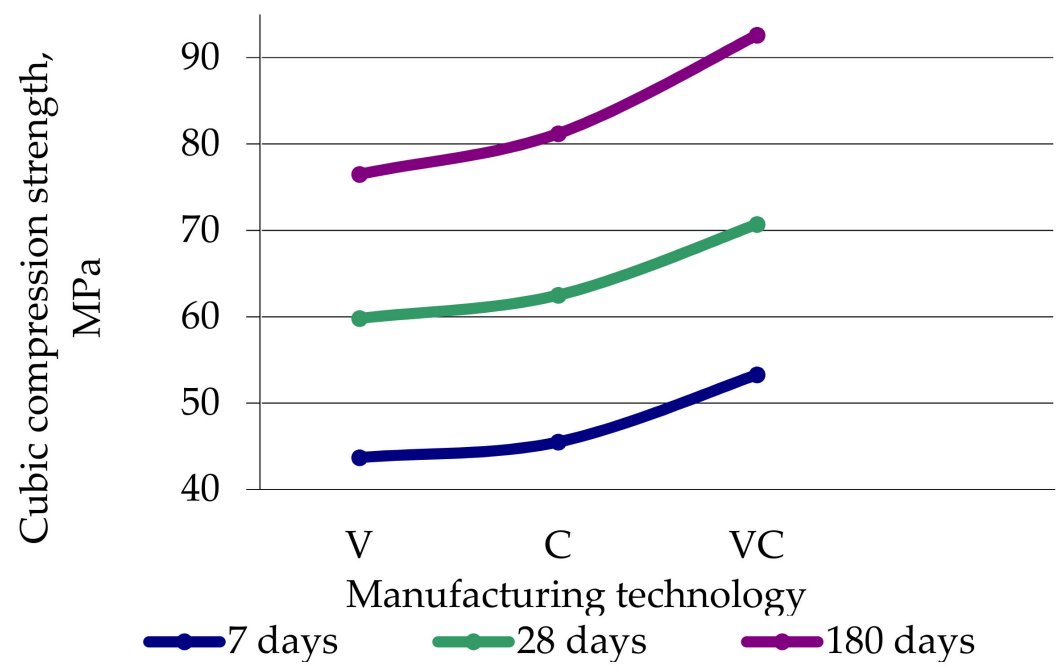

Figure 11. Dependence of the cubic compression strength of concrete on the manufacturing technology.

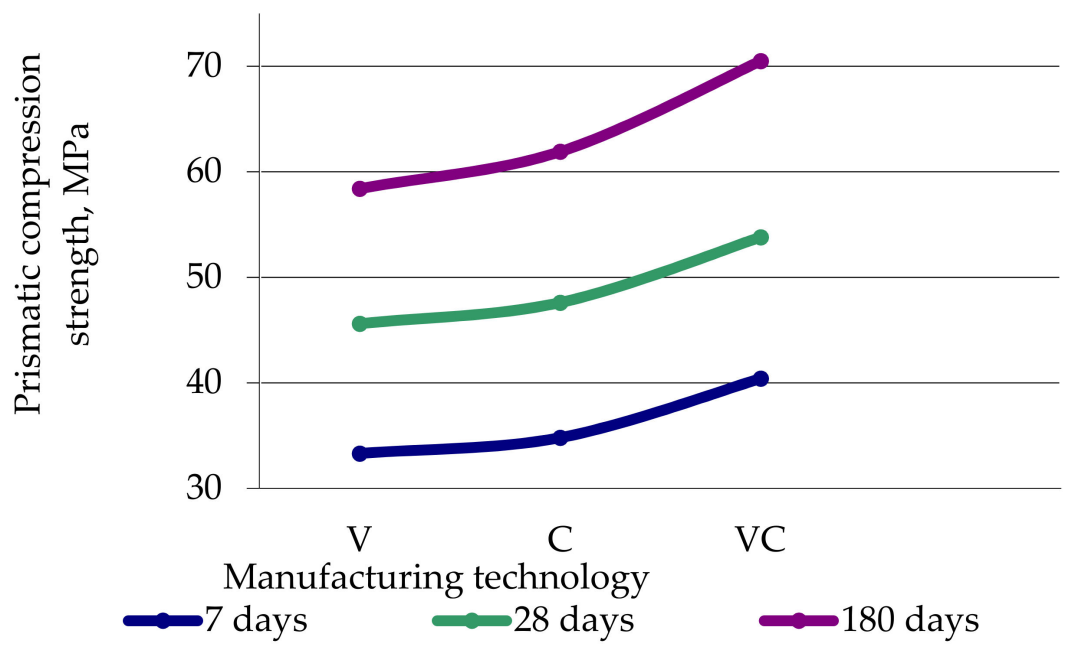

Figure 12. Dependence of the prismatic strength of concrete at axial compression on the manufacturing technology.

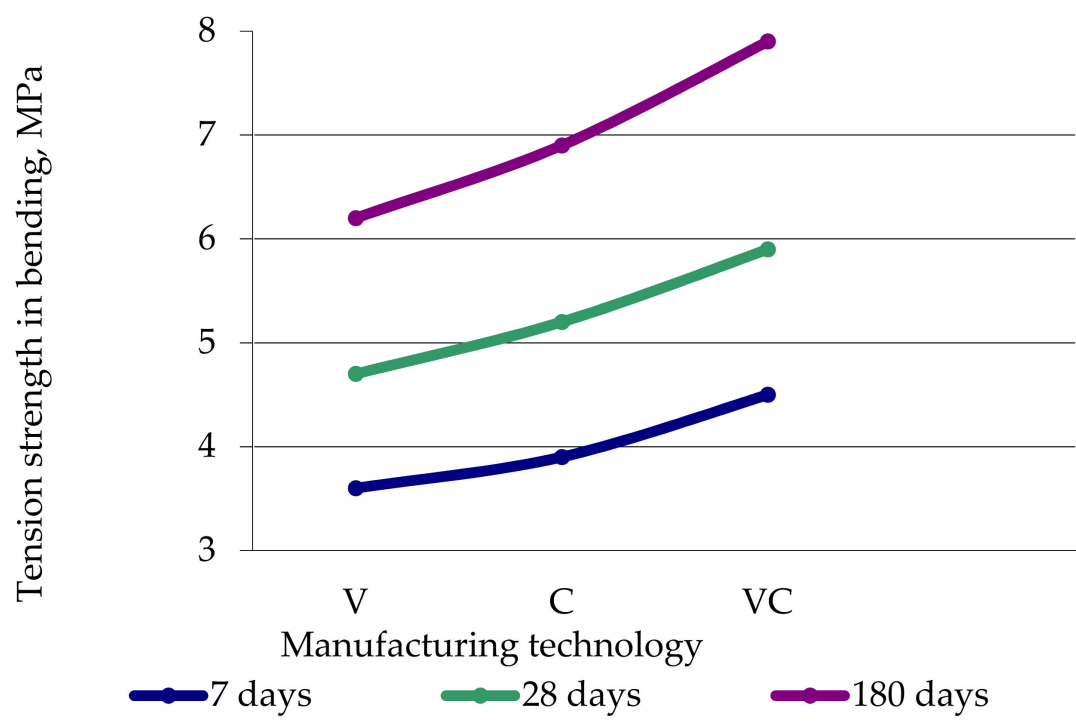

Figure 13. Dependence of the tension strength of concrete in bending on the manufacturing technology. 


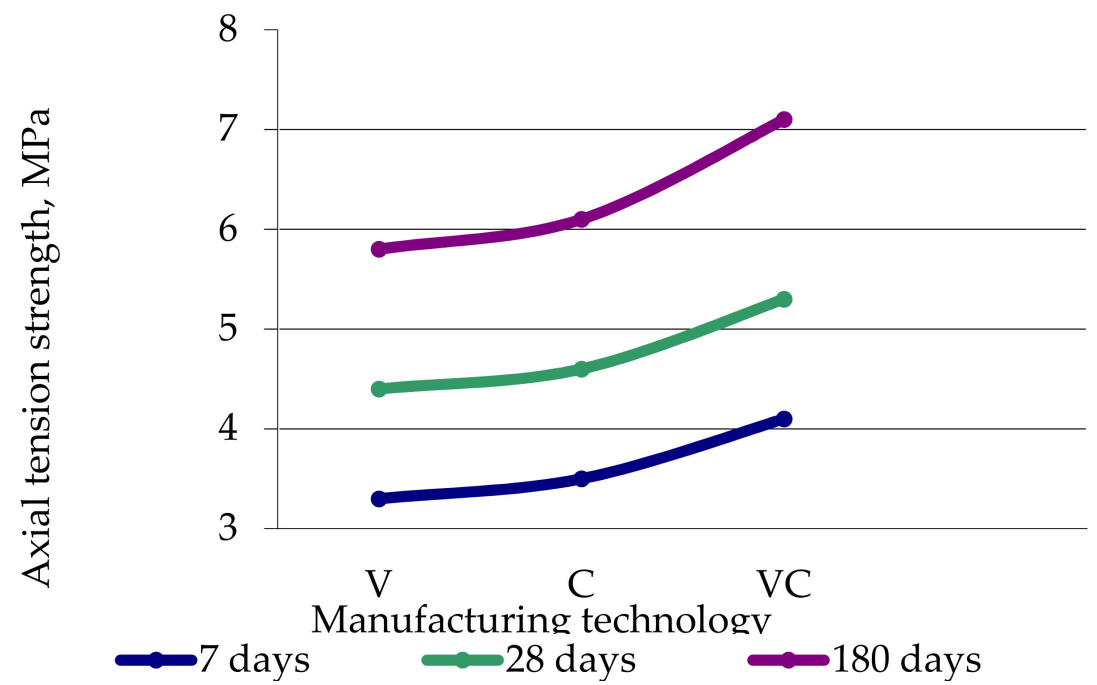

Figure 14. Dependence of the axial tension strength of concrete on the manufacturing technology.

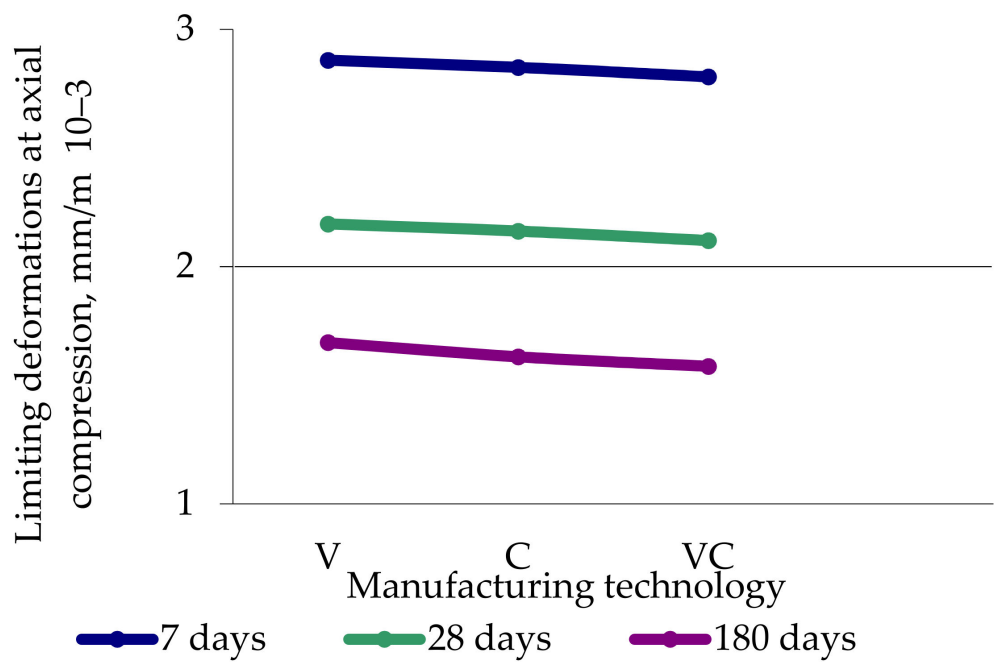

Figure 15. Dependence of the limiting strains of concrete at axial compression on the manufacturing technology.
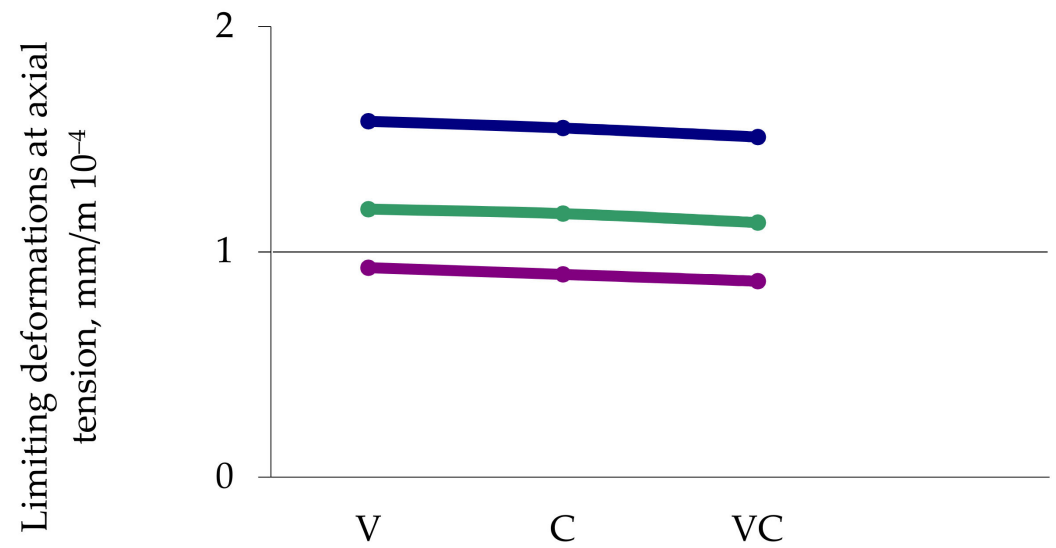

Manufacturing technology

$$
\text { 7 days } \quad 28 \text { days } \quad \longrightarrow \text { 180 days }
$$

Figure 16. Dependence of the limiting strains of concrete at axial tension on the manufacturing technology. 


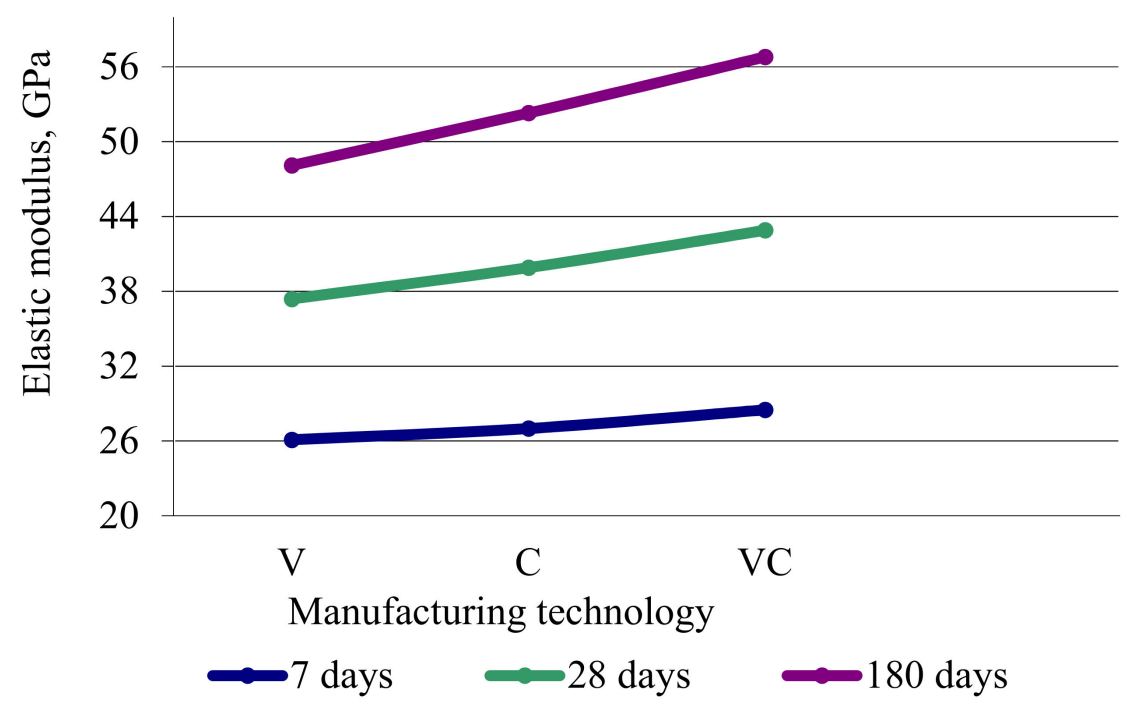

Figure 17. Dependence of the elasticity modulus of concrete on the manufacturing technology.

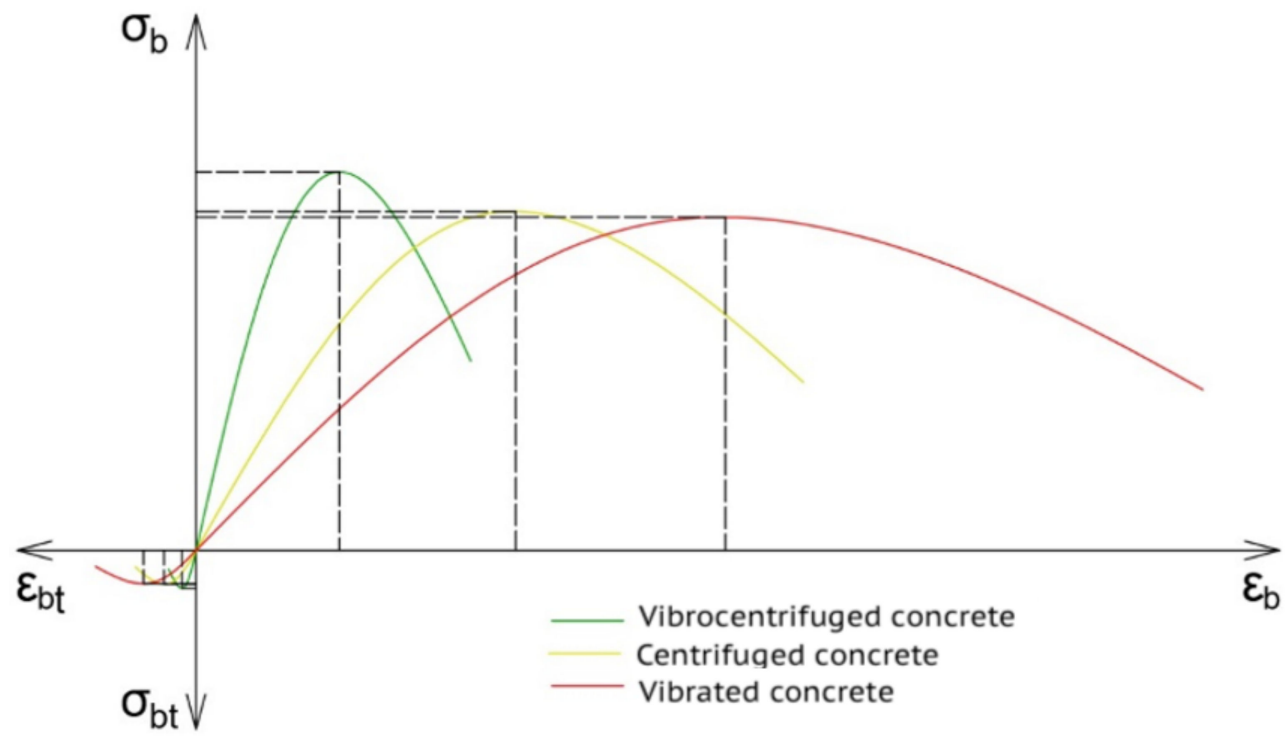

Figure 18. Principal dependences of the " $\sigma-\varepsilon$ " diagrams of concrete on the technology of their manufacture.

5.1.2. Analysis of Integral Density, Strength, Limiting Deformations, Elasticity Modulus and Deformation Diagrams of Concrete in Compression and Tension

Analysis of the obtained experimental results shown in Table 2 and Figures 10-18 allowed us to draw the following conclusions.

The density (Table 1 and Figure 10) practically did not depend much (within $2 \%$ ) on the technology of their manufacture at all values of age; therefore, the technology can be ignored when calculating the density assessment.

The compression and tension strength of vibro-centrifuged concretes at any age was noticeably higher compared to centrifuged and vibrated concretes. This is applied to both cubic and prismatic compression strength (up to 22.0\%, see Table 2, Figures 11 and 12), and axial tension and flexural tension strength (up to 26.6\%, see Table 2, Figures 13 and 14).

The excess of the compression and tension strength of the vibro-centrifuged concretes in comparison with the vibrated and centrifuged concretes grows with the age of concrete and is approximately in the same range at all values of age of concrete, namely from 7 to 180 days, which is explained by the ordering of the continuing processes of hydration in the cement stone during this entire period. 
The values of limiting strains under axial compression and tension (corresponding to the maximum strength of concrete) showed the opposite picture, namely they decreased at all ages in vibro-centrifuged concretes, compared with centrifuged and vibrated concretes, although these reductions were, in general, insignificant and were within $6 \%$ (see Table 2 , Figures 15 and 16).

We only noted that all values of limiting strains in the vibro-centrifuged concretes both as at axial compression as axial tension were lesser at any age compared with corresponding values for centrifuged and vibrated concretes.

The modulus of elasticity in compression $E_{b}$ and tension $E_{b t}$ in the vibro-centrifuged concretes in comparison with the centrifuged and vibrated concretes at all times of hardening were up to $7.4 \%$ higher (see Table 2, Figure 17).

An increase in the initial modulus of elasticity in compression and tension was explained by an increase in strength with a simultaneous decrease in the limiting strains of the vibro-centrifuged concretes in comparison with the centrifuged and vibrated concretes (Figure 18).

Diagrams "stress-strain" under compression and tension in the vibro-centrifuged concretes in comparison with the centrifuged and vibrated concretes at all ages were characterized by the following features:

(i) The maximum shifts were up and to the left (strength increases, and limiting strain decrease);

(ii) The angle of rise at the origin of coordinates increases (initial modulus of elasticity increases).

Thus, the tilt angle of the ascending branch increases in the diagrams, the descending branch is longer evident for the vibrated concretes, but for the centrifuged concretes and especially for the vibro-centrifuged concretes, it decreases (Figure 18). This picture was observed at all values of age of concretes.

In Table 2, the corresponding deviations were calculated as follows:

$$
\begin{aligned}
& \Delta_{1}=\frac{\mathrm{C}-\mathrm{V}}{\mathrm{V}} \times 100 \%, \\
& \Delta_{2}=\frac{\mathrm{VC}-\mathrm{V}}{\mathrm{V}} \times 100 \%, \\
& \Delta_{3}=\frac{\mathrm{VC}-\mathrm{C}}{\mathrm{C}} \times 100 \% .
\end{aligned}
$$

Corresponding parameters in (10) are related to vibrated (V), centrifuged (C) and vibrocentrifuged (VC) concrete samples.

\subsection{Study of Differential Design Characteristics of Centrifuged and Vibro-Centrifuged Concretes of Variatropic Sections}

As shown above, during centrifugation and vibro-centrifugation of samples with sufficiently thick walls, the centrifugal and centripetal forces acting on the outer, middle and inner layers of the cross-section are very different, which leads to a significant difference in the structure and characteristics of these layers of the sample, which in some cases must be taken into account in the calculations [42-44,46-49]. Therefore, after study of the influence of manufacturing technology (vibration, centrifugation, vibro-centrifugation) on integral (common) characteristics of concrete, we investigated the variatropy of the structure of experimental concrete samples of annular cross-section and the associated differential design characteristics of concrete layers.

Since the previously obtained integral (common) results for all three technologies gave the characteristics averaged on cross-section of the concrete of the test samples as a whole, we also studied the characteristics of each of the three conditional separate layers (outer, middle and inner) of the test samples with the annular cross-section, the characteristics of which differed from each other due to centrifugation and vibro-centrifugation. Note that vibrated test samples for differential design characteristics were not investigated due to the absence of cross-section variatropy in them. 


\subsection{Features of Experimental Research Methods for Differential Characteristics of Concrete by Ultrasonic Method}

Thus, with the exception of the vibrated test samples, the centrifuged and vibrocentrifuged samples in their cross-sections were variatropic, that is, they were a combination of conditional layers of one sample, the properties and characteristics of which differed from each other due to the manufacturing technology. The schedule and methodology for experimental studies of the differential structural characteristics of concrete have been detailed above. However, in order to obtain more detailed data, the following instrumental approach was additionally applied.

To reveal the change in the properties of the samples in contact layers, we additionally applied ultrasonic sounding using the device Pulsar 2.2. This method has been described above, and based on the results, it was concluded that it could be used for centrifuged and vibro-centrifuged samples of a variatropic structure.

For this purpose, three prisms, each with dimensions of $1200 \times 150 \times 50 \mathrm{~mm}^{3}$ were conditionally distinguished in the wall of each sample. The device sensors were attached on all three conditional layers (inner, middle and outer) of the variatropic structure along the cross-section wall thickness according to the scheme in Figure 19. The described studies were carried out for all concrete samples during centrifugation and vibro-centrifugation.

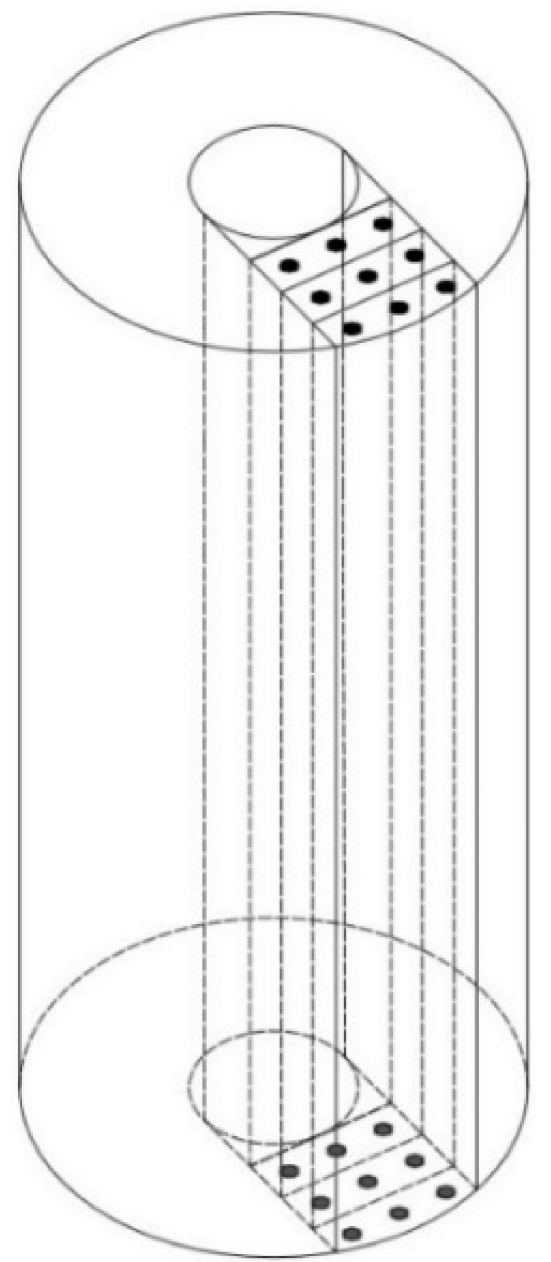

Figure 19. Places for installation of the sensors of the ultrasonic device.

Table 3 shows the qualitative and quantitative pictures of the distribution of density and strength of the centrifuged and vibro-centrifuged concretes. 
Table 3. Results of sounding layers of prototypes.

\begin{tabular}{|c|c|c|c|c|c|c|}
\hline \multirow{4}{*}{ Characteristic } & \multicolumn{6}{|c|}{ Technology } \\
\hline & \multicolumn{3}{|c|}{ Centrifugation } & \multicolumn{3}{|c|}{ Vibro-Centrifugation } \\
\hline & \multicolumn{3}{|c|}{ Layer } & \multicolumn{3}{|c|}{ Layer } \\
\hline & External & Middle & Interior & External & Middle & Interior \\
\hline Ultrasound speed, $\mathrm{m} / \mathrm{s}$ & 4432 & 4054 & 3785 & 4710 & 4561 & 4110 \\
\hline Density, $\mathrm{kg} / \mathrm{m}^{3}$ & 2495 & 2403 & 2316 & 2544 & 2492 & 2396 \\
\hline Compression strength, $\mathrm{MPa}$ & 43.4 & 35.5 & 32.2 & 68.2 & 65.1 & 41.6 \\
\hline Elastic modulus, GPa & 34.3 & 27.8 & 24.8 & 38.8 & 35.2 & 28.5 \\
\hline
\end{tabular}

It can be seen from Table 3 that, confirming the theoretical calculations, the outer layer of the sample, which was affected by the maximum centrifugal force, had the greatest strength both during centrifugation and vibro-centrifugation, and the inner layer had the least value. However, for centrifuged concrete, the plot of strength changes by layers (from outer to inner) took the form of a descending curve (Figure 20) with a bulge down. For vibro-centrifuged concrete, the plot of changes in strength by layers (from outer to inner) also took the form of a descending curve (Figure 21), but with a bulge upward.
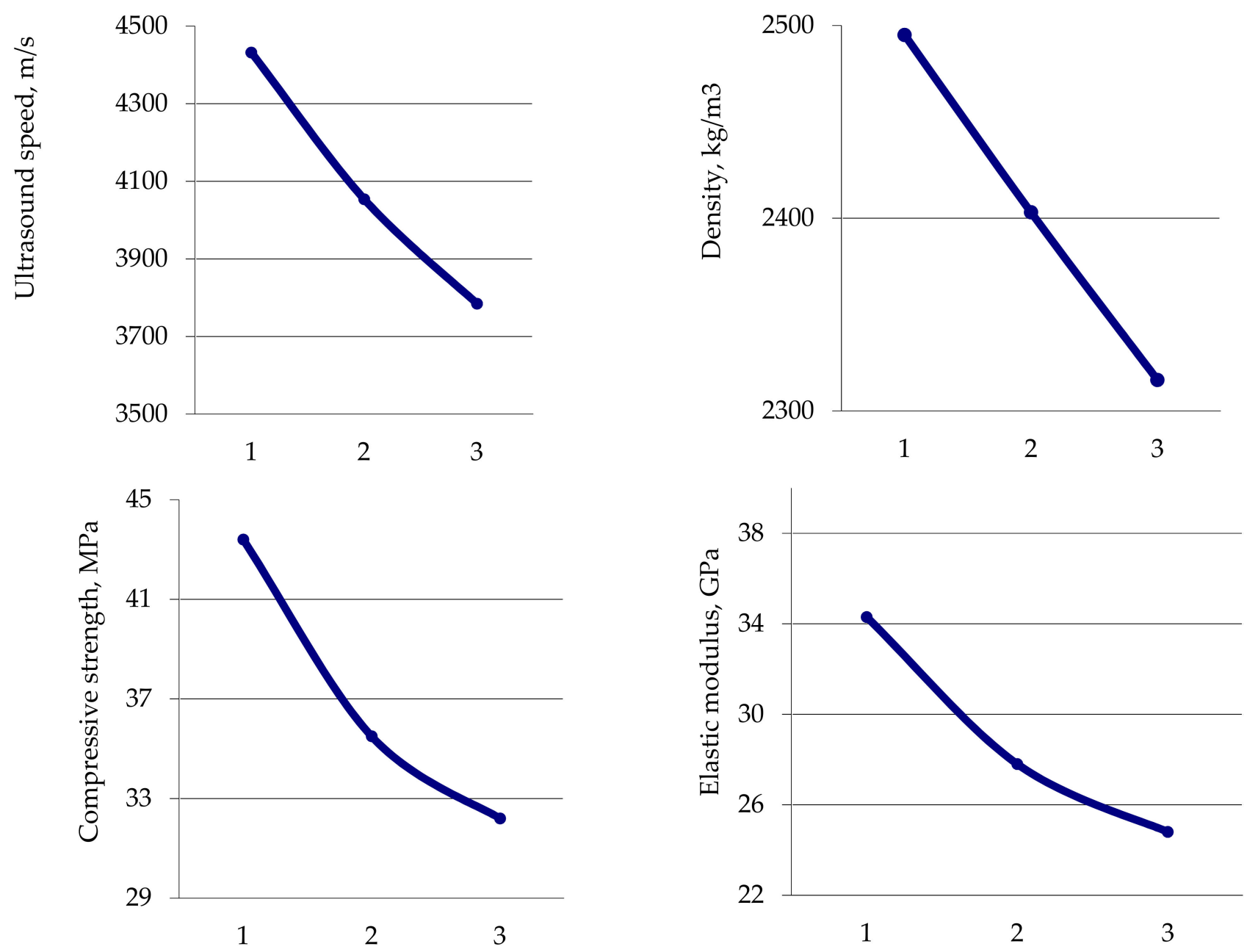

Figure 20. Plots of the distribution of ultrasound speed, density, strength and elastic modulus by layers during centrifugation: 1-outer layer; 2-middle layer; 3-inner layer. 

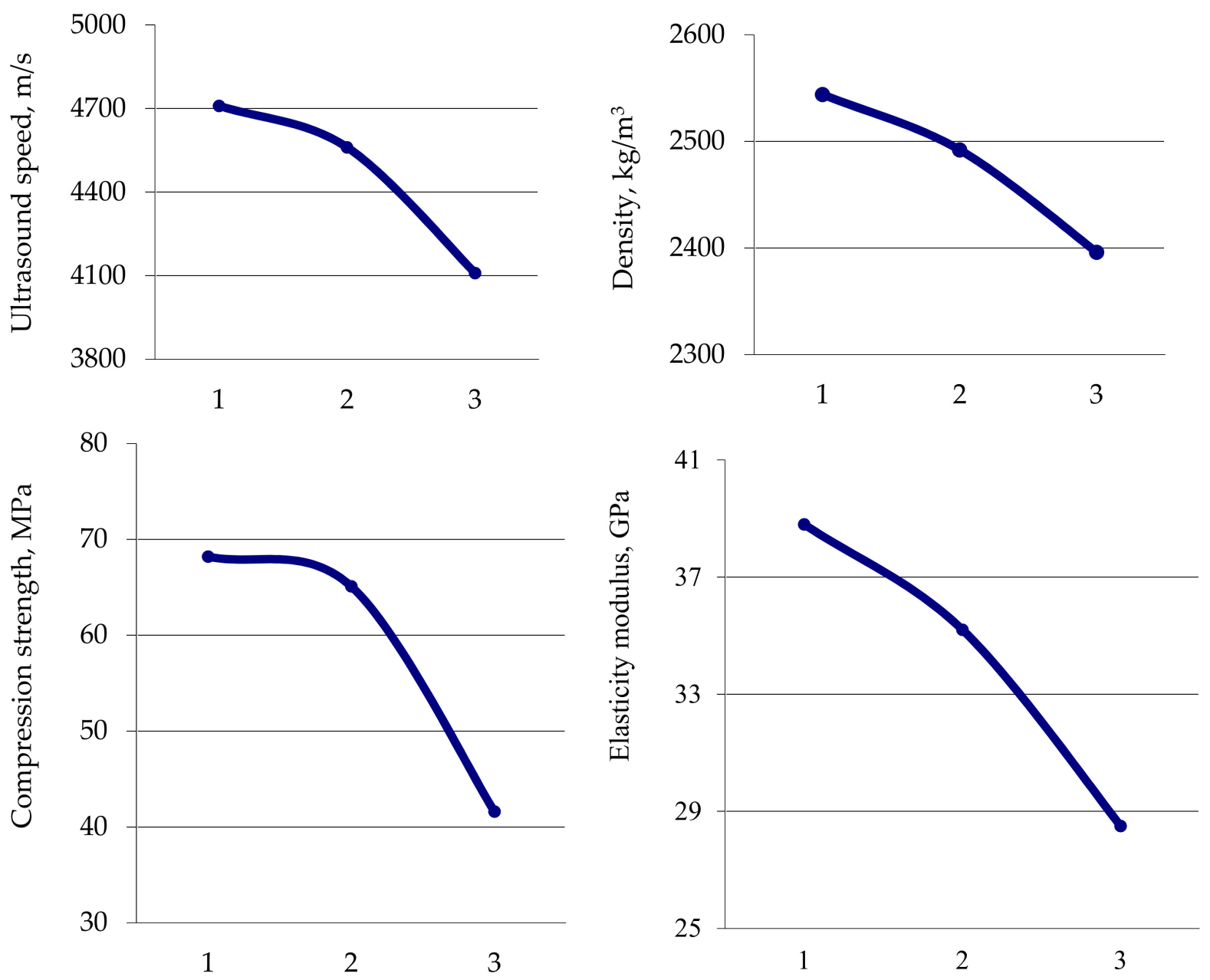

Figure 21. Plots of the distribution of ultrasound speed, density, strength and elastic modulus by layers during vibrocentrifugation: 1 -outer layer; 2 -middle layer; 3-inner layer.

In other words, if, by centrifuging concrete, the middle layer shows an intermediate strength between the outer and inner layers, but less than the arithmetic mean value between the strength characteristics of the outer and inner layers, then during vibrocentrifugation, the middle layer also shows an intermediate strength between the outer and inner layers, but greater, than the arithmetic mean value between the strength characteristics of the outer and inner layers. This leads to the reverse change in the convexity of the strength curve by layers (see Figures 20 and 21).

Thus, experimentally we have confirmed the substantiation of the three-layer variatropic structure of the computational model of the vibro-centrifuged and centrifuged concretes.

Theoretically, the deformations of concrete layers and their moduli of elasticity also undergo similar changes. The concrete of the outer layer should have the highest modulus of elasticity, while the concrete of the inner layer, on the contrary, should have a minimum modulus of elasticity, and the modulus of elasticity of the middle layer will occupy an intermediate position between them in value, somewhat less at centrifugation and more at vibro-centrifugation.

For strains, the picture will be reversed. Accordingly, all above results lead to differences in the " $\sigma-\varepsilon$ " diagrams of various concrete layers.

All the above results also confirm the variatropy of the structure and the validity of the three-layer structure of the design model of centrifuged or vibro-centrifuged concrete of structures, which must be taken into account in the calculations. 


\section{Conclusions}

The results of the work are the determination of the hidden reserves of heavy concrete. This will save developers from the need to lay a very large margin of safety in the designed products.

Thus, savings in reinforcement and high-performance, expensive concrete components will be achieved. Thus, this will lead to a reduction in the cost, rationalization and optimization of building structures, the use of low-material-intensive structures and the construction of low-energy buildings and structures. Ultimately, this will be cost-effective and efficient in terms of calculation, design and manufacture of such structures.

The main results are as follows:

1. Experimental methods and instrumental apparatuses were developed for studies of the centrifuged and vibro-centrifuged concrete products with annular cross-sections, which made it possible to assess the picture of the real variatropy of the structure and confirmed that the accepted direction of research was correct.

2. An original method of experimental studies of the variatropy of cross-sections of the vibrated, centrifuged and vibro-centrifuged concretes was proposed to determine their integral (common) and differential (differing in layers) strength, strain characteristics and deformation diagrams.

3. The experimental studies of the integral characteristics of the vibrated, centrifuged and vibro-centrifuged concretes at the age of 7, 28 and 180 days under compression and tension revealed the following:

(i) The characteristics of concretes are higher after vibro-centrifugation compared with centrifugation and vibration, and after centrifugation they are better than after vibration;

(ii) The compression and tension strength increase at all ages up to values of 20-22\%;

(iii) The limiting strains at axial compression and axial tension decrease up to values of $6-8 \%$;

(iv) The modulus of elasticity at axial compression and axial tension increases up to values of $5-10 \%$.

4. It was proved that it becomes possible to obtain concretes with improved structure and higher characteristics at vibro-centrifugation compared with centrifugation and vibration.

5. The experimental studies of the differential characteristics of centrifuged and vibrocentrifuged concretes at compression and tension revealed that the outer layer of concrete has the best characteristics during centrifugation and vibro-centrifugation, and the inner layer has the worst.

6. The experimental study confirmed a three-layer model variatropic concrete structure. Differentiation of the characteristics of layers of variatropic concrete was obtained: (i) the concrete of the outer layers has the highest strength, modulus of elasticity and the least deformability; (ii) the concrete of the inner layers has the lowest strength, modulus of elasticity and the highest deformability; (iii) the concrete of the middle layers has average characteristics.

7. The diagrams of deformation for the centrifuged and vibro-centrifuged concretes are also differentiated by layers, confirming the variatropy of the structure of such concretes. Of these, the deformation diagrams for the outer concrete layer are the highest in strength, the deformation diagrams for the inner concrete layer are the smallest in strength, and the middle concrete layer demonstrates mean deformation diagrams.

Author Contributions: Conceptualization, L.R.M.; methodology, S.A.S., E.M.S. and A.K.K.; formal analysis, S.A.S., E.M.S., A.K.K. and A.V.C.; investigation, A.S.S. and A.K.S.; writing-original draft preparation, S.A.S., E.M.S., A.K.K. and A.V.C.; writing-review and editing, I.A.P. and A.V.C. All authors have read and agreed to the published version of the manuscript. 
Funding: This research was funded by a grant from the Ministry of Science and Higher Education of Russia supported by Southern Federal University, grant No. VnGr-07/2020-04-IM.

Institutional Review Board Statement: Not applicable.

Informed Consent Statement: Not applicable.

Data Availability Statement: Data is contained within the article.

Acknowledgments: The authors acknowledge the support by the Southern Federal University, grant No. VnGr-07/2020-04-IM (Ministry of Science and Higher Education of Russia).

Conflicts of Interest: The authors declare no conflict of interest.

\section{References}

1. Podolsky, V.I. Reinforced Concrete Supports of the Electric Contact Network. Design, Operation, Diagnostics; All-Russian ScientificResearch Institute of Rail-Road Transport: Moscow, Russia, 2007; p. 152. (In Russian)

2. Suleimanova, L.A. High-quality energy-saving and competitive building materials, products and structures. Bull. BSTU Named VG Shukhov. 2017, 1, 9-16. (In Russian)

3. Akhverdov, I.N. Fundamentals of Concrete Physics; Stroyizdat: Moscow, Russia, 1981; p. 464. (In Russian)

4. Liu, Z.; Chen, X.; Wu, P.; Cheng, X. Investigation on micro-structure of self-compacting concrete modified by recycled grinded tire rubber based on X-ray computed tomography technology. J. Clean. Prod. 2021, 290, 125838. [CrossRef]

5. Vorobeichikov, S.E.; Fokin, V.A.; Udod, V.A.; Temnik, A.K. A study of two image-recognition algorithms for the classification of flaws in a test object according to its digital image. Russ. J. Nondestruct. Test. 2015, 51, 644-651. [CrossRef]

6. Dimarogonas, A.D. Vibration of cracked structures: A state of the art review. Eng. Fract. Mech. 1996, 55, 831-857. [CrossRef]

7. Dado, M.H.; Shpli, O.A. Crack parameter estimation in structures using finite element modeling. Int. J. Solids Struct. 2003, 40, 5389-5406. [CrossRef]

8. Bamnios, Y.; Douka, E.; Trochidis, A. Crack identification in beam structures using mechanical impedance. J. Sound Vib. 2002, 256, 287-297. [CrossRef]

9. Cherpakov, A.V.; Shlyakhova, E.A.; Egorochkina, I.O.; Kokareva, Y.A. Identification of Concrete Properties in Beam-Type Structures with Defects Based on Dynamic Methods. Mater. Sci. Forum 2018, 931, 373-378. [CrossRef]

10. Shevtsov, S.N.; Soloviev, A.N.; Parinov, I.A.; Cherpakov, A.V.; Chebanenko, V.A. Piezoelectric Actuators and Generators for Energy Harvesting-Research and Development; Series: Innovation and Discovery in Russian Science and Engineering; Springer: Cham, Switzerland, 2018; p. 182. ISBN 978-3319756288.

11. Akopyan, V.A.; Rozhkov, E.V.; Soloviev, A.N.; Shevtsov, S.N.; Cherpakov, A.V. Identification of Damages in Elastic Structures: Approaches, Methods, Analysis; Southern Federal University Press: Rostov-on-Don, Russia, 2015; p. 74. (In Russian)

12. Wang, Z.; Man, X.T.C.; Finch, R.D.; Jansen, B.H. The Dynamic Behavior and Vibration Monitoring of Reinforced Concrete Beams. J. Test. Eval. 1998, 26, 405-419. [CrossRef]

13. Orlov, V.; Chichurin, A. On the theory of constructing a numerical-analytical solution of a cantilever beam bend nonlinear differential equation of the first order. J. Phys. Conf. Ser. 2019, 1425, 012129. [CrossRef]

14. Krasnoshchekov, A.A.; Sobol', B.V.; Solov'Ev, A.N.; Cherpakov, A.V. Identification of crack-like defects in elastic structural elements on the basis of evolution algorithms. Russ. J. Nondestruct. Test. 2011, 47, 412-419. [CrossRef]

15. Cherpakov, A.V.; Soloviev, A.N.; Gritsenko, V.V.; Goncharov, O.U. Damages Identification in the Cantilever-based on the Parameters of the Natural Oscillations. Def. Sci. J. 2016, 66, 44-50. [CrossRef]

16. Popovics, J.S. Comment on "Determination of elastic constants of a concrete specimen using transient elastic waves" [J. Acoust. Soc. Am. 98, 2142-2148 (1995)]. J. Acoust. Soc. Am. 1996, 100, 3451. [CrossRef]

17. Popovics, J.; Rose, J. An approach for wave velocity measurement in solid cylindrical rods subjected to elastic impact. Int. J. Solids Struct. 1996, 33, 3925-3935. [CrossRef]

18. Ponzo, F.; Di Cesare, A.; Telesca, A.; Pavese, A.; Furinghetti, M. Advanced Modelling and Risk Analysis of RC Buildings with Sliding Isolation Systems Designed by the Italian Seismic Code. Appl. Sci. 2021, 11, 1938. [CrossRef]

19. Akopyan, V.A.; Solov'Ev, A.N.; Cherpakov, A.V.; Shevtsov, S.N. On a deformation sign for identifying defects on the basis of the analysis of the forms of the natural vibrations of a cantilever with a notch. Russ. J. Nondestruct. Test. 2013, 49, 579-583. [CrossRef]

20. Grigoryan, M.N.; Polyakova, T.V.; A Kokareva, Y.; A Parinov, I.; Cherpakov, A.V. The technical state experimental studies of construction with free support in the non-stationary oscillations' analysis. IOP Conf. Ser. Mater. Sci. Eng. 2021, $1083,012016$. [CrossRef]

21. Garnier, V.; Corneloup, G.; Sprauel, J.; Perfumo, J. Setting time study of roller compacted concrete by spectral analysis of transmitted ultrasonic signals. NDT E Int. 1995, 28, 15-22. [CrossRef]

22. Gaydeckp, P.; Burdekin, F. nondestructive testing of reinforced and pre-stressed concrete structures. Nondestruct. Test. Eval. 1998, 14, 339-392. [CrossRef]

23. Kwon, H.; Joh, C.; Chin, W. Pulse Peak Delay-Total Focusing Method for Ultrasonic Tomography on Concrete Structure. Appl. Sci. 2021, 11, 1741. [CrossRef] 
24. Brigante, M.; Sumbatyan, M.A. Acoustic methods for the nondestructive testing of concrete: A review of foreign publications in the experimental field. Russ. J. Nondestruct. Test. 2013, 49, 100-111. [CrossRef]

25. Brigante, M.; Sumbatyan, M.A. Acoustic methods in nondestructive testing of concrete: Review of foreign publications in the field of theoretical studies. Russ. J. Nondestruct. Test. 2013, 49, 185-195. [CrossRef]

26. Kovler, K.; Schamban, I. Mathematical methods of experimental design in Nondestructive. Test. NDT Net 2000, 5. Available online: https: / / www.ndt.net/article/v05n02/kovler/kovler.htm (accessed on 1 March 2021).

27. Jurowski, K.; Grzeszczyk, S. Influence of Selected Factors on the Relationship between the Dynamic Elastic Modulus and Compressive Strength of Concrete. Materials 2018, 11, 477. [CrossRef] [PubMed]

28. Salman, M.M.; Al-Amawee, A.H. The Ratio between Static and Dynamic Modulus of Elasticity in Normal and High Strength Concrete. J. Eng. Dev. 2006, 10, 163-174.

29. Tatarinov, A.; Rumjancevs, A.; Mironovs, V. Assessment of cracks in pre-stressed concrete railway sleepers by ultrasonic testing. Procedia Comput. Sci. 2019, 149, 324-330. [CrossRef]

30. Kim, G.; Loreto, G.; Kim, J.-Y.; Kurtis, K.E.; Wall, J.J.; Jacobs, L.J. In situ nonlinear ultrasonic technique for monitoring microcracking in concrete subjected to creep and cyclic loading. Ultrasonics 2018, 88, 64-71. [CrossRef]

31. Pahlavan, L.; Zhang, F.; Blacquière, G.; Yang, Y.; Hordijk, D. Interaction of ultrasonic waves with partially-closed cracks in concrete structures. Constr. Build. Mater. 2018, 167, 899-906. [CrossRef]

32. Kakavas-Papaniaros, P.; Baros, D.; Kalapodis, N.; Anifantis, N. Prediction of mechanical properties of thick concrete members or masonries utilizing ultrasonics. Procedia Struct. Integr. 2018, 10, 311-318. [CrossRef]

33. Antonaci, P.; Bruno, C.; Gliozzi, A.; Scalerandi, M. Monitoring evolution of compressive damage in concrete with linear and nonlinear ultrasonic methods. Cem. Concr. Res. 2010, 40, 1106-1113. [CrossRef]

34. Saint-Pierre, F.; Philibert, A.; Giroux, B.; Rivard, P. Concrete Quality Designation based on Ultrasonic Pulse Velocity. Constr. Build. Mater. 2016, 125, 1022-1027. [CrossRef]

35. Nobile, L.; Nobile, S. Some Recent Advances of Ultrasonic Diagnostic Methods Applied to Materials and Structures (Including Biological Ones). Phys. Procedia 2015, 70, 681-685. [CrossRef]

36. Patil, S.; Reddy, D.M. Impact damage assessment in carbon fiber reinforced composite using vibration-based new damage index and ultrasonic C-scanning method. Structures 2020, 28, 638-650. [CrossRef]

37. Hoła, J.; Schabowicz, K. State-of-the-art non-destructive methods for diagnostic testing of building structures-Anticipated development trends. Arch. Civ. Mech. Eng. 2010, 10, 5-18. [CrossRef]

38. Sun, H.; Zhu, J. Nondestructive evaluation of steel-concrete composite structure using high-frequency ultrasonic guided wave. Ultrasonics 2020, 103, 106096. [CrossRef] [PubMed]

39. Lee, T.; Lee, J. Setting time and compressive strength prediction model of concrete by nondestructive ultrasonic pulse velocity testing at early age. Constr. Build. Mater. 2020, 252, 119027. [CrossRef]

40. Lootens, D.; Schumacher, M.; Liard, M.; Jones, S.Z.; Bentz, D.P.; Ricci, S.; Meacci, V. Continuous strength measurements of cement pastes and concretes by the ultrasonic wave reflection method. Constr. Build. Mater. 2020, 242, 117902. [CrossRef]

41. Lin, S.; Shams, S.; Choi, H.; Azari, H. Ultrasonic imaging of multi-layer concrete structures. NDT E Int. 2018, 98, 101-109. [CrossRef]

42. Shuyskiy, A.I.; Stel'Makh, S.A.; Shcherban', E.M.; Kholodnyak, M.G. Investigation of the Influence of the Initial Composition of Heavy Concrete Designed for the Manufacture of Ring-Section Products on its Properties. Mater. Sci. Forum 2018, 931, 508-514. [CrossRef]

43. Stel'Makh, S.A.; Shcherban', E.M.; Shuyskiy, A.I.; Nazhuev, M.P. Theoretical and Practical Aspects of the Formation of the Variational Structure of Centrifuged Products from Heavy Concrete. Mater. Sci. Forum 2018, 931, 502-507. [CrossRef]

44. Stel'makh, S.A.; Shcherban', E.M.; Kholodnyak, M.G. Analysis of concrete deformation diagram, received by different ways of formation, and their separate layers. IOP Conf. Ser. Mater. Sci. Eng. 2019, 687, 022008. [CrossRef]

45. Shchutsky, V.L.; Gritsenko, M.Y.; Dedukh, D.A. Investigation of the Physical and Mechanical Properties of Centrifuged Concrete. Eng. J. Don 2015, 4. Available online: http:/ /www.ivdon.ru/en/magazine/archive/n2p2y2015/3000 (accessed on 1 March 2021).

46. Stel'makh, S.A.; Scherban', E.M.; Korobkin, A.P.; Tkacheva, K.E.; Osadchenko, S.A.; Kadrov, A.A. Study of changes in strength properties along section thickness of high-strength centrifuged and vibro-centrifuged concrete. IOP Conf. Ser. Mater. Sci. Eng. 2020, 905, 012060. [CrossRef]

47. Shcherban', E.M.; Stel'makh, S.A.; Efimenko, E.A. Deformability and features of destruction of centrifuged concrete during shock loads. AIP Conf. Proc. 2019, 2188, 060002. [CrossRef]

48. Mailyan, L.R.; Stel'makh, S.A.; Shcherban', E.M.; Nazhuev, M.P. Setting a diagram approach to calculating vibrated, centrifuged and vibrocentrifuged reinforced concrete columns with a variatropic structure. Russ. J. Build. Constr. Archit. 2021, 49, 30-44. [CrossRef]

49. Mailyan, L.R.; Stel'makh, S.A.; Shcherban', E.M.; Kholodnyak, M.G. Determination and use of hidden strength reserves of centrifuged reinforced constructions by means of calculation and experimental methods. Russ. J. Build. Constr. Archit. 2020, 45, 6-14. 